\title{
NOTCH-1 and NOTCH-4 are novel gene targets of PEA3 in breast cancer: novel therapeutic implications
}

\author{
Anthony G Clementz ${ }^{1}$, Allison Rogowski ${ }^{2}$, Kinnari Pandya², Lucio Miele ${ }^{3}$ and Clodia Osipo 1,2,4,5,6*
}

\begin{abstract}
Introduction: Women with triple-negative breast cancer have the worst prognosis, frequently present with metastatic tumors and have few targeted therapy options. Notch-1 and Notch-4 are potent breast oncogenes that are overexpressed in triple-negative and other subtypes of breast cancer. PEA3, an ETS transcription factor, is also overexpressed in triple-negative and other breast cancer subtypes. We investigated whether PEA3 could be the critical transcriptional activator of Notch receptors in MDA-MB-231 and other breast cancer cells.
\end{abstract}

Methods: Real-time PCR and Western blot analysis were performed to detect Notch-1, Notch-2, Notch-3 and Notch4 receptor expression in breast cancer cells when PEA3 was knocked down by siRNA. Chromatin immunoprecipitation was performed to identify promoter regions for Notch genes that recruited PEA3. TAM-67 and c-Jun siRNA were used to identify that c-Jun was necessary for PEA3 enrichment on the Notch-4 promoter. A Notch-4 luciferase reporter was used to confirm that endogenous PEA3 or AP-1 activated the Notch-4 promoter region. Cell cycle analysis, trypan blue exclusion, annexin V flow cytometry, colony formation assay and an in vivo xenograft study were performed to determine the biological significance of targeting PEA3 via siRNA, Notch signaling via a $\gamma$-secretase inhibitor, or both.

Results: Herein we provide new evidence for transcriptional regulation of Notch by PEA3 in breast cancer. PEA3 activates Notch-1 transcription in MCF-7, MDA-MB-231 and SKBr3 breast cancer cells. PEA3 activates Notch-4 transcription in MDA-MB-231 cells where PEA3 levels are endogenously high. In SKBr3 and BT474 breast cancer cells where PEA3 levels are low, overexpression of PEA3 increases Notch-4 transcripts. Chromatin immunoprecipitation confirmed the enrichment of PEA3 on Notch-1 and Notch-4 promoters in MDA-MB-231 cells. PEA3 recruitment to Notch-1 was AP-1-independent, whereas PEA3 recruitment to Notch-4 was c-JUN-dependent. Importantly, the combined inhibition of Notch signaling via a $\gamma$-secretase inhibitor (MRK-003 GSI) and knockdown of PEA3 arrested growth in the $G_{1}$ phase, decreased both anchorage-dependent and anchorage-independent growth and significantly increased apoptotic cells in vitro. Moreover, either PEA3 knockdown or MRK-003 GSI treatment significantly reduced tumor growth of MDA-MB-231 xenografts in vivo.

Conclusions: Taken together, the results from this study demonstrate for the first time that Notch-1 and Notch-4 are novel transcriptional targets of PEA3 in breast cancer cells. Targeting of PEA3 and/or Notch pathways might provide a new therapeutic strategy for triple-negative and possibly other breast cancer subtypes.

\footnotetext{
* Correspondence: cosipo@lumc.edu

1 Molecular and Cellular Biochemistry Program, Loyola University Medical

Center, Maywood, IL 60153, USA

Full list of author information is available at the end of the article
} 


\section{Introduction}

Breast cancer continues to be the second leading cause of cancer-related deaths among women worldwide. Approximately $70 \%$ of breast cancers are estrogen receptor $\alpha$-positive $\left(E R \alpha^{+}\right)$and progesterone receptor-positive $\left(\mathrm{PR}^{+}\right)$. They are divided into two subtypes: luminal $\mathrm{A}$, comprising those that are negative for the overexpression or gene amplification of ErbB-2/HER2 and have low levels of genes responsible for proliferation, and luminal $\mathrm{B}$, comprising those that are positive for HER2 and have high expression of proliferation-associated genes $[1,2]$. This division is in part due to their sensitivity to antihormonal therapy such as tamoxifen or an aromatase inhibitor. The luminal A subtype carries the best prognosis, followed by luminal B. The third subtype is $\mathrm{ER}^{-} / \mathrm{PR}^{-}$and $\mathrm{HER}^{+}$, which contains gene amplification for the $\operatorname{ErbB}$ $2 / H E R 2$ oncogene. The HER $2^{+}$subtype represents $15 \%$ to $25 \%$ of breast cancers and is currently treated with trastuzumab plus a taxane-based chemotherapy. The $\mathrm{HER}^{+}$subtype of breast cancer is associated with excellent survival outcomes due to adjuvant trastuzumab therapy, a humanized monoclonal antibody that targets the HER2 receptor [3]. However, $30 \%$ to $60 \%$ of metastatic HER2 ${ }^{+}$breast cancer are resistant to trastuzumab. The fourth subtype of breast cancer is the normal-like subtype, which resembles normal mammary epithelial cells expressing genes associated with adipose tissue. The fifth subtype represents $15 \%$ of breast cancers and is triplenegative, and thus lacks expression of ER/PR and HER2. Triple-negative breast cancers carry the worst prognosis because of the lack of US Food and Drug Administration-approved targeted therapies [4,5]. Thus, there is an immediate need for the elucidation of novel targets to treat women with triple-negative breast cancer and to increase these patients' overall survival.

Notch signaling has emerged as a target for the treatment of breast cancer [6]. In the mammalian system, there are four Notch receptors (Notch-1, Notch-2, Notch-3 and Notch-4) [7] and five known ligands (Delta-like 1, Deltalike 3 and Delta-like 4 and Jagged-1 and Jagged-2) [8-10]. Cell-to-cell contact is critical for the activation of Notch signaling, which subsequently enables the pathway to modulate genes involved in cell fate such as proliferation or differentiation [11]. Notch is processed in the transGolgi apparatus, where it undergoes the first of three proteolytic cleavages. The single polypeptide is cleaved (S1) by furin-like convertase forming the mature Notch receptor, which is a heterodimer consisting of Notch extracellular (NEC) and Notch transmembrane (NTM). The receptor is trafficked to the plasma membrane, where it awaits engagement with its membrane-associated ligand. Upon ligand-receptor engagement, the second cleavage (S2) by a disintegrin and metalloproteases 10 and 17
(ADAM10 and ADAM17, respectively) [12] releases NEC to be endocytosed into the ligand-expressing cell. Subsequently, NTM is cleaved (S3) by the $\gamma$-secretase complex, liberating the intracellular portion of Notch (NIC) [13]. NIC translocates to the nucleus and binds to CBF-1, a constitutive transcriptional repressor, displacing corepressors and recruiting coactivators such as Mastermind $[14,15]$. Notch activates many genes associated with differentiation and/or survival, including, but not limited to, the HES and HEY family of basic helix-loop-helix transcription factors [16], cyclin D1 [17] and c-Myc [18]. The third and final cleavage step is critical for active Notch signaling. Its inhibition can be exploited through emerging pharmacological drugs identified as $\gamma$-secretase inhibitors (GSIs), which attenuate signaling from all four receptors. Recent studies have demonstrated that GSI treatment suppresses breast tumor growth in a variety of breast cancer subtypes [19-23], providing evidence of novel therapeutic approaches.

The first evidence that Notch receptors are breast oncogenes was provided by mouse studies. Overexpression of constitutive, active forms of Notch-1 (N1IC) or Notch-4 (N4IC) form spontaneous murine mammary tumors in vivo [11]. Furthermore, elevated expression of Notch-1 and/or its ligand Jagged-1 in human breast tumors is associated with the poorest overall patient survival [24-26]. Recently, Notch-4 has been shown to be critical for the survival of tumor-initiating cells [27]. Similarly to studies performed using Notch-1, mouse mammary tumor virus (MMTV)-driven Notch-3 receptor intracellular domain expression in transgenic mice showed enhanced mammary tumorigenesis [28]. In HER2- breast cancers, downregulation of Notch-3 resulted in suppressed proliferation and increased apoptosis [29]. In contrast, overexpression of Notch-2 in MDA-MB-231 cells significantly decreased tumor growth and increased apoptosis in vivo [30], suggesting that Notch-2 is a breast tumor suppressor.

The factors that regulate Notch receptor expression in breast cancer cells are still widely unknown. It has been shown that p53 binds to the Notch-1 promoter and activates Notch-1 receptor transcription in human keratinocytes [31]. Activator protein 1 (AP-1) has been demonstrated to be a transcriptional activator of Notch4 in human vascular endothelial cells [32]. We asked which factors regulate Notch receptor transcription in breast cancer.

Polyomavirus enhancer activator 3 (PEA3/E1AF/ ETV4) is a member of the ETS family of transcription factors, which also includes ERM and ER-81. PEA3 is overexpressed in metastatic breast carcinomas, particularly triple-negative breast tumors [33]. PEA3 regulates critical genes involved in inflammation and invasion, such as IL-8 [34], cyclooxygenase-2 (COX-2) [35] and 
matrix metalloproteases (MMPs) [36-39]. A dominantnegative form of PEA3 reduced tumor onset and growth in a MMTV/neu-transgenic model of breast cancer in vivo [40]. PEA3 contains an ETS winged helix-turn-helix DNA binding motif [41] that binds to the canonical sequence GGAA/T on target genes [42]. The affinity of binding relies on proximal sequences surrounding the ETS binding site which aid in transcriptional control based on context [43]. Phosphorylation of serine and threonine residues by the mitogen-activating protein kinase cascade activates PEA3 and is negatively regulated by the ubiquitin-proteasome pathway as well as by sumoylation [44-46].

The transcriptional activity of PEA3 is dependent on other activators to regulate gene transcription and is commonly partnered with AP-1 to regulate genes such as MMP-1, MMP-3, MMP-7 and MMP-9 [36]; urokinase-type plasminogen activator (uPA) [47]; COX-2 [35]; and ErbB-2 [48]. AP-1 is a dimeric complex consisting of the Fos (c-FOS, FosB, Fra-1 and Fra-2) and Jun (c-JUN, JunB and JunD) families [49]. Depending on the cellular context, AP-1 cooperates with other proteins including, but not limited to, $\mathrm{NF} \kappa \mathrm{B}, \mathrm{CBP} / \mathrm{p} 300, \mathrm{Rb}$ and PEA3 [50,51]. The functional role of AP-1 is to recruit and direct appropriate factors to regulate gene expression and promote proliferation, differentiation, inflammation and/or apoptosis [52].

Previous investigations have determined that overexpression of Notch-1 and Notch-4 plays a critical role in breast tumorigenesis [11] and that PEA3 overexpression is associated with aggressive breast cancers, particularly the triple-negative subtype [53-58]. Herein we provide novel evidence of a link between two pathways that are overexpressed in breast cancer. PEA3 is a transcriptional activator of Notch-1 and Notch-4 and a repressor of Notch-2 in MDA-MB-231 cells, an example of triplenegative breast cancer cells. PEA3-mediated Notch-1 transcription is AP-1-independent, while Notch-4 transcription requires both PEA3 and c-JUN. PEA3 and/or Notch signaling are essential for proliferation, survival and tumor growth of MDA-MB-231 cells. Furthermore, PEA3 is a transcriptional activator of both Notch-1 and Notch-4 in other breast cancer cells. Thus we hypothesized that targeting of the PEA3 and/or Notch pathways might provide a new therapeutic strategy for triple-negative breast cancer as well as possibly other breast cancer subtypes where PEA3 regulates Notch-1 and/or Notch4.

\section{Materials and methods}

\section{Cell culture and reagents}

MDA-MB-231, SKBr3, BT474 and MCF-7 breast cancer cells were purchased from the American Type Culture Collection (Manassas, VA, USA). All cell lines were supplemented with $100 \mu \mathrm{mol}$ nonessential amino acids and $1 \% \mathrm{~L}$-glutamine. SKBr3 cells (supplemented with $10 \%$ fetal bovine serum (FBS)) and MDA-MB-231 cells (supplemented with 5\% FBS) were maintained in Iscove's Minimal Essential Medium (IMEM). MCF-7 cells (supplemented with 10\% FBS) were maintained in DMEM/Ham's Nutrient Mixture F-12. BT474 cells (supplemented with $10 \% \mathrm{FBS}$ ) were maintained in DMEM. All cells were cultured in a $37^{\circ} \mathrm{C}$ incubator with $5 \%$ $\mathrm{CO}_{2}$. MRK-003 GSI was kindly provided by Merck Oncology International, Inc. (33 Avenue Louis Pasteur, Boston, MA, USA). MRK-003 GSI was dissolved in dimethylsulfoxide (DMSO) and stored at $-80^{\circ} \mathrm{C}$ until use. Lactacystin (L6785) was purchased from SigmaAldrich (St Louis, MO, USA), dissolved in deionized water and stored at $-20^{\circ} \mathrm{C}$ until use. The pcDNA3.1 expression vector and the PEA3-pcDNA3.1 expression vector were kindly provided by Dr Mein-Chie Hung (The University of Texas MD Anderson Cancer Center, Houston, TX, USA). The pHMB empty and pHMBTAM-67 expression vectors were kindly provided by $\mathrm{Dr}$ Richard Schultz, Department of Immunology and Microbiology, (Loyola University Medical Center, Maywood, IL, USA).

\section{RNA interference and reagents}

Control scrambled siRNA-a (sc-37007), Notch-1 siRNA (sc-36095), and a smart pool of three distinct PEA3 siRNA (PEA3ia, sc-36205) were purchased from Santa Cruz Biotechnology (Santa Cruz, CA, USA). An unrelated control siRNA and PEA3 siRNA (PEA3ib, catalog number 115237) were purchased from Ambion (Austin, TX, USA). A smart pool of four distinct c-Jun siRNA (sc-29223) were purchased from Santa Cruz Biotechnology (Santa Cruz, CA, USA). Transfection reagents used were Lipofectamine 2000 and Lipofectamine RNAiMAX, which were purchased from Invitrogen (Carlsbad, CA, USA), and FuGENE 6 was purchased from Roche Diagnostics Corporation (Indianapolis, IN, USA). Protocols were performed as described by the manufacturers.

\section{Antibodies}

Notch-1 (antibody clone C-20), Notch-4 (antibody clone H-225), PEA3 [16] (product number sc-113), c-JUN (antibody clone G-4) were purchased from Santa Cruz Biotechnology. $\beta$-actin (antibody clone AC-15) was purchased from Sigma-Aldrich and used as the loading control

\section{Real-time RT-PCR}

Total RNA was extracted from the cells using the RNeasy Mini Kit (Qiagen, Valencia, CA, USA) according to the manufacturer's protocol. Total cDNA was reverse-transcribed from the total RNA with random 
hexamers using the MultiScribe ${ }^{\mathrm{TM}}$ Reverse Transcriptase Kit (Applied Biosystems, Foster City, CA, USA) according to the manufacturer's protocol. Analysis of transcript relative fold copy number adjusted to hypoxanthineguanine phosphoribosyl transferase (HPRT), an endogenous control, was carried out by quantitative real-time PCR using iTaq ${ }^{\mathrm{TM}}$ SYBR Green Supermix with ROX (Bio-Rad Laboratories, Hercules, CA, USA) and the PlusOne thermal cycler from Applied Biosystems. The following primers were used for detection: Notch-1 (forward primer: 5'-GTCAACGCCGTAGATGACC-3', reverse primer: 5'-TTGTTAGCCCCGTTCTTCAG-3'), Notch-2 (forward primer: 5'-TCCACTTCATACTCACAGTTGA-3', reverse primer: 5'-TGGTTCAGAGAA AACATACA-3'), Notch-3 (forward primer: 5'-GGGAA AAAGGCAATAGGC-3', reverse primer: 5'-GGAGGGAGAAGCCAAGTC-3'), Notch-4 (forward primer: 5'-AACTCCTCCCCAGGAATCTG-3', reverse primer: 5'-CCTCCATCCAGCAGAGGTT-3'), PEA3 (forward primer: 5'-AGGAGACGTGGCTCGCTGA-3'), (reverse primer: 5'-GGGGCTGTGGAAAGCTAGGTT-3'), HEY1 (forward primer: 5'-TGGATCACCTGAAAATGCTG3', reverse primer: 5'-TTGTTGAGATGCGAAACCAG3'), MMP-9 (forward primer: 5'-TCGTGGTTCCA ACTCGGTTT-3', reverse primer: 5'-GCGGCCCT CGAAGATGA-3') and IL-8 (forward primer: 5'CACCGGAAGGAACCATCTCACT-3', reverse primer: 5'-TCAGCCCTCTTCAAAAACTTCTCC-3'), with HPRT (forward primer: 5'-ATGAACCAGGTTATGACCTTGAT-3', reverse primer: 5'-CCTGTTGACTGG TCATTACAATA-3') used as the loading control. Protocols were performed as described by the manufacturers. Transfection conditions for Western blot analysis and RT-PCR were as follows. MDA-MB-231 $\left(4 \times 10^{5}\right)$, MCF-7 $\left(4 \times 10^{5}\right), \operatorname{SKBr} 3\left(5 \times 10^{5}\right)$ and BT474 $\left(5 \times 10^{5}\right)$ cells were placed into a six-well culture dish. Twentyfour hours later the cells were transfected with reagents. Forty-eight hours later cells were harvested and protein/ RNA was extracted. Notch-4 luciferase constructs were generously provided by Dr Emery Bresnick, Cell \& Regenerative Biology, (University of Wisconsin at Madison, Madison, WI, USA). The AP-1 luciferase construct was generously provided by Dr Richard Schultz, Department of Immunology and Microbiology,(Loyola University Medical Center, Maywood, IL, USA). Dual-luciferase assays were performed as described by the manufacturer (Promega, Madison, WI, USA). A pRL-thymidine kinase promoter-driven Renilla luciferase reporter was cotransfected with the Firefly luciferase construct mentioned above as an internal transfection control. Transfection activity was measured using the Veritas Microplate Luminometer (Turner Biosystems, Sunnyvale, CA, USA) and represented as the ratio of Firefly luciferase to Renilla luciferase.

\section{Western blot analysis}

The cells were lysed in radioimmunoprecipitation assay buffer ( $\mathrm{pH} 8.0$ ) containing $50 \mathrm{mmol}$ Tris $\mathrm{HCl}, 150 \mathrm{mmol}$ $\mathrm{NaCl}, 1 \%$ Nonidet P-40 (NP-40), 0.5\% sodium deoxycholate, $0.1 \%$ SDS, $25 \mathrm{mmol} \beta$-glycerophosphate, $1 \mathrm{mmol}$ sodium orthovanadate, $1 \mathrm{mmol}$ sodium fluoride, $1 \mathrm{mmol}$ phenylmethylsulfonyl fluoride, $1 \mathrm{mg} / \mathrm{mL}$ aprotinin and $1 \mathrm{mg} / \mathrm{mL}$ leupeptin. Western blot analysis was performed as previously described [21]. NuPAGE Bis-Tris Gels (4\% to $12 \%$; Invitrogen) in 3-(N-morpholino)propanesulfonic acid buffer were run at $175 \mathrm{~V}$ for 1.5 hours, and proteins were transferred at $38 \mathrm{~V}$ for 2 hours using polyvinylidene fluoride membranes. Protein detection was performed using the SuperSignal West Dura Substrate (Thermo Scientific, Rockford, IL, USA) and visualized by using the FUJIFILM $^{\mathrm{TM}}$ Las-300 imager (GE-Healthcare Bio-Sciences, Piscataway, NJ, USA).

\section{Chromatin immunoprecipitation}

MDA-MB-231 cells $\left(3 \times 10^{6}\right)$ were plated in $150-\mathrm{cm}^{2}$ Petri dishes. Twenty-four hours later cells were transfected with pcDNA3.1, PEA3-pcDNA3.1 and PEA3pcDNA3.1, together with PEA3 siRNA, for 48 hours. The cells were cross-linked with $1 \%$ formaldehyde and lysed in SDS lysis buffer (1\% SDS, $10 \mathrm{mmol}$ ethylenediaminetetraacetic acid (EDTA), $50 \mathrm{mmol}$ Tris $\mathrm{HCl}, \mathrm{pH} 8.1$ ). The lysates were sonicated using the Branson Sonifier model 250 (Branson Ultrasound Corp., Danbury, CT, USA) at output 4.5 , duty cycle 50 , and pulsed 10 times. The lysate was then diluted 1:10 in immunoprecipitation dilution buffer (0.01\% SDS, 1.1\% Triton X-100, 1.2 mmol EDTA, $16.7 \mathrm{mmol}$ Tris $\mathrm{HCl}, 167 \mathrm{mmol} \mathrm{NaCl}, \mathrm{pH}$ 8.1). Approximately 300 to $700 \mu \mathrm{g}$ of total precleared protein in lysates were incubated with $4 \mu \mathrm{g}$ of PEA3 antibody (sc-113X; Santa Cruz Biotechnology) or mouse immunoglobulin G (IgG) overnight. Fifty microliters of protein G-plus agarose beads (sc-2002; Santa Cruz Biotechnology) were added to the immune complexes for 2 hours while gently rocking. Immune complexes/beads were washed in lowsalt buffer (0.1\% SDS, 1\% Triton X-100, 2 mmol EDTA, $20 \mathrm{mmol}$ Tris $\mathrm{HCl}, 150 \mathrm{mmol} \mathrm{NaCl}, \mathrm{pH} 8.1$ ), high-salt buffer $(0.1 \%$ SDS, $1 \%$ Triton X-100, 2 mmol EDTA, $20 \mathrm{mmol}$ Tris $\mathrm{HCl}, 500 \mathrm{mmol} \mathrm{NaCl}, \mathrm{pH} 8.1$ ), LiCl buffer ( $1 \%$ sodium deoxycholate, $1 \% \mathrm{NP}-40,0.25 \mathrm{~mol} \mathrm{LiCl}$, $1 \mathrm{mmol}$ EDTA, $10 \mathrm{mmol}$ Tris $\mathrm{HCl}, \mathrm{pH} \mathrm{8.1)}$ and TrisEDTA buffer ( $1 \mathrm{mmol}$ EDTA and $10 \mathrm{mmol}$ Tris $\mathrm{HCl})$ at $4^{\circ} \mathrm{C}$ with agitation. The protein/antibody complexes from beads were eluted in freshly prepared elution buffer ( $1 \%$ SDS, 0.1 mol sodium bicarbonate, $\mathrm{pH}$ 8.0). Cross-linking of proteins and DNA was reversed by heating at $65^{\circ} \mathrm{C}$ overnight while gently rocking. The protein was degraded using a proteinase solution $(0.5 \mathrm{~mol}$ EDTA, $1 \mathrm{M}$ Tris $\mathrm{HCl}, \mathrm{pH} 8.0,10 \mathrm{mg} / \mathrm{mL}$ proteinase $\mathrm{K}$ ) and incubated at $52^{\circ} \mathrm{C}$ for 1 hour. DNA was isolated using the QIAquick 
PCR purification kit (Qiagen). Enrichment at promoter sites was detected by quantitative PCR using $\mathrm{iTaq}^{\mathrm{TM}}$ SYBR Green Supermix with ROX (Bio-Rad Laboratories). $C_{\mathrm{t}}$ threshold values were normalized to the IgG control. The following promoter region primers were used in detection: Notch-1 promoter regions not containing ETS or AP-1 sequences served as negative controls (forward primer: 5'-GTGCACACGGCTGTCCG-3', reverse primer: 5'-GCGACAACTGGCGACTGAA-3'), 2× PEA3 (forward primer: 5'-GCTGCAAGAGCCAAGATGAA-3', reverse primer: 5'-GGTGCCTGTGTTGAAAGCTCT-3'), c-ETS (forward primer: 5'-CTCCTGGCGCTTAACCAGG-3', reverse primer: 5'-CCAGAAAGCACAAACG GGTC-3'), AP-1(A) (forward primer: 5'-GCCTCCTT AGCTCACCCTGA-3'), reverse primer (5'-TCTTCAGAGGCCCCCTGC-3'), AP-1(B) (forward primer: 5'-TC CGCAAACCAGGCTCTG-3', reverse primer: 5'-ATTGG GGTGCAGTGCCG-3'), Sp-1/PEA3 (forward primer: 5'CACCTCGACTCTGAGCCTCAC-3', reverse primer: 5'CTCTTCCCCGGCTGGCT-3'). Notch-4 promoter regions not containing ETS or AP-1 sequences served as negative controls (forward primer: 5'-GGCGAGGATTCTAATGTGGA-3', reverse primer: 5'-CCCTGA GTGAA AGGGTGAAG-3'), CBF-1 (forward primer: 5'-TGGTA CCACCCTGGTCAGTAT-3', reverse primer: 5'-TGCT CAGGCATTATGAGCTATG-3'), AP-1(A) (forward primer: 5'-AGCTGCCACTGACACCTTCT-3', reverse primer: 5'-CAGGGAATGCCAGTCAGAAT-3'), AP-1(B) (forward primer: 5'-ACTTCCCCAGGGG TTGTC-3', reverse primer: 5'-CTTCCTCCTCGGC CTGCT-3') and PEA3/ETS (forward primer: 5'-GGGTTCCTCTTC CCCATACC-3', reverse primer: 5'-TCATTT TCCCATCACСТTССТТ-3').

\section{Coimmunoprecipitation}

MDA-MB-231 cells $\left(3 \times 10^{6}\right)$ were plated in $150-\mathrm{cm}^{2}$ Petri dishes for 24 hours. The cells were transfected with pcDNA3.1, PEA3-pcDNA3.1 and PEA3-pcDNA3.1, together with PEA3 siRNA, for 48 hours. The cells were cross-linked with $1 \%$ formaldehyde and lysed in SDS lysis buffer (1\% SDS, $10 \mathrm{mmol}$ EDTA, $50 \mathrm{mmol}$ Tris $\mathrm{HCl}$, pH 8.1). The lysates were sonicated using the Branson Sonifier 250 at output 4.5, duty cycle 50, and pulsed 10 times. The lysate concentration was ascertained and was equally diluted in immunoprecipitation dilution buffer $(0.01 \%$ SDS, 1.1\% Triton X-100, $1.2 \mathrm{mmol}$ EDTA, $16.7 \mathrm{mmol}$ Tris $\mathrm{HCl}, 167 \mathrm{mmol} \mathrm{NaCl}, \mathrm{pH} 8.1$ ). Approximately 300 to $700 \mu \mathrm{g}$ of total precleared lysates were incubated with $3 \mu \mathrm{g}$ of PEA3 antibody (sc-113X; Santa Cruz Biotechnology) or mouse IgG overnight. Thirty microliters of protein G-plus agarose beads (sc-2002, Santa Cruz Biotechnology) were added to the immune complexes for 2 hours while gently rocking. Immune complexes and beads were washed three times in PBS. The pellet was resuspended in Laemmli sample buffer with $5 \% \beta$-mercaptoethanol (Bio-Rad Laboratories) and heated for 5 minutes at $95^{\circ} \mathrm{C}$ while vigorously shaking. Western blot analysis was used to detect coimmunoprecipitation proteins as described above. Antibodies used for detection were PEA3 (16), c-FOS (H-125), c-JUN (G-4) and Fra-1 (R-20).

\section{Cell cycle analysis}

MDA-MB-231 cells $\left(1 \times 10^{5}\right)$ were seeded into a six-well plate. After 24 hours, the cells were treated/transfected with DMSO/scrambled, control siRNA, DMSO/PEA3 siRNA, MRK-003 (10 $\mu \mathrm{mol}) /$ scrambled siRNA or MRK$003(10 \mu \mathrm{mol}) /$ PEA3 siRNA. Briefly, 24 and 48 hours posttreatment/posttransfection, the cells and media were isolated and permeabilized with $70 \%$ ethanol. The cells were then pelleted, washed in $5 \%$ bovine calf serum and resuspended in $10 \mu \mathrm{g} / \mathrm{mL}$ RNase/PBS solution. The cells were stained with propidium iodide $(100 \mu \mathrm{g} / \mathrm{mL})$ and analyzed by flow cytometry (FACSCanto; BD Biosciences, San Jose, CA, USA).

\section{Annexin V}

MDA-MB-231 cells $\left(1.5 \times 10^{5}\right)$ were seeded into a six-well plate for 24 hours. Cells were treated/transfected with DMSO/scrambled siRNA, DMSO/PEA3 siRNA, MRK-003 $(10 \mu \mathrm{mol}) / \mathrm{scrambled}$ siRNA and MRK-003 $(10 \mu \mathrm{mol}) /$ PEA3 siRNA. Briefly, after 24 and 48 hours of treatment/ transfection, $1 \times 10^{6}$ cells were isolated in $1 \times$ annexin binding buffer (0.1 mol 4-(2-hydroxyethyl)-1-piperazineethanesulfonic acid/ $\mathrm{NaOH}, 140 \mathrm{~mol} \mathrm{NaCl}, 25 \mathrm{mmol}$ $\mathrm{CaCl}_{2}, \mathrm{pH}$ 7.4) and treated with both fluorescein isothiocyanate-annexin V stain and propidium iodide. After 1hour incubation, the samples were subjected to analysis by flow cytometry (FACSCanto; BD Biosciences).

\section{Cell viability assay}

MDA-MB-231 cells $\left(1.5 \times 10^{5}\right)$ were seeded into a sixwell plate for 24 hours. Cells were treated/transfected with DMSO/scrambled siRNA, DMSO/PEA3 siRNA, MRK-003 (10 $\mu \mathrm{mol}) / \mathrm{scrambled}$ siRNA and MRK-003 $(10 \mu \mathrm{mol}) /$ PEA3 siRNA. Briefly, after 24 and 48 hours of treatment/transfection, cells and media were harvested and washed in PBS. The cells were stained with trypan blue and counted under a standard slide microscope at $\times 40$ magnification.

\section{Colony formation assay}

In a six-well plate, a bottom layer of $1 \mathrm{~mL}$ of $0.8 \%$ agar dissolved in IMEM was added. Two milliliters of a $2 \%$ methylcellulose/IMEM solution (supplemented with 5\% FBS, 1\% nonessential amino acids and $1 \%$ L-glutamine) were added on top of the agar. MDA-MB-231 cells $\left(1 \times 10^{3}\right.$ cells $\left./ \mathrm{mL}\right)$ were treated/transfected with DMSO/scrambled siRNA, DMSO/PEA3 siRNA, MRK-003 (5 $\mu \mathrm{mol}) / \mathrm{scrambled}$ 
siRNA or MRK-003 (5 $\mu \mathrm{mol}) /$ PEA3 siRNA for 24 hours. Treated cells were added directly to the methylcellulose solution. The assay was left untouched for 14 days at $37^{\circ} \mathrm{C}$ and $5 \% \mathrm{CO}_{2}$. Colonies were stained with crystal violet for 1 hour, photographed and counted under a standard light microscope at $\times 40$ magnification. Nine fields per well were counted.

\section{MDA-MB-231 xenograft study}

MDA-MB-231 cells were transfected in vitro with control or PEA3 siRNA smart pool for 24 hours as described previously. One million cells were subsequently injected into each of two mammary fat pads of $10 \mathrm{Balb} / \mathrm{c}$ athymic nude mice per group, for a total of 40 mice. The mice were randomized to control siRNA or PEA3 siRNA and fed orally by gavage, vehicle control ( $2 \%$ carboxymethylcellulose in sterile PBS) or $100 \mathrm{mg} / \mathrm{kg}$ MRK-003 GSI for three consecutive days per week. The tumor areas were measured using vernier calipers, and growth rates were calculated by linear regression analysis. The tumor areas were monitored biweekly for up to 3.5 weeks. The protocols used to study breast tumor xenografts in mice were approved by Loyola University's Institutional Animal Care and Use Committee.

\section{Results}

\section{PEA3 regulates Notch-1, Notch-2 and Notch-4 receptor transcripts}

To investigate the role of PEA3 in Notch expression, we examined the effect of two independent PEA3 RNA interference sequences on the expression of Notch-1 through Notch-4 receptor mRNA as measured by real-time PCR. Notch-1 and Notch-4 transcripts were decreased by nearly $50 \%$ and $70 \%$, respectively, upon PEA3 knockdown by either PEA3ia or PEA3ib siRNA. Notch-3 transcript levels remained unchanged. Interestingly, Notch-2 levels showed a moderate but significant increase upon PEA3 knockdown, which, upon further investigation, may prove to be advantageous, since it has been correlated with proapoptotic and breast tumor suppressive function [30] (Figure 1A, lower left graphs). PEA3 transcripts were measured as a control for the efficacy of PEA3 knockdown using the two types of PEA3 siRNA (Figure 1A, upper left graph).

To determine whether the effect on Notch-1 and Notch-4 transcripts correlated with protein expression, protein lysates from cells transfected with either a scrambled, control siRNA (SCRBia) or PEA3 siRNA (PEA3ia) for 48 hours were subjected to Western blot analysis. The results showed a reduction of Notch-1 full-length and transmembrane receptor protein levels by $50 \%$ (Figure $1 \mathrm{~B}$, upper right panel). To visualize the effects of PEA3 siRNAa on the rapidly turned over Notch-4 receptor, we treated MDA-MB-231 cells with or without lactacystin, a specific proteasome inhibitor, for 24 hours before lysing cells for total proteins. Consequently, N4IC protein levels were decreased by $90 \%$ upon PEA3 knockdown (Figure 1B, upper right panel).

To confirm the effect of PEA3 siRNAa on the levels and activity of PEA3, PEA3 and its classical downstream targets were measured by real-time PCR after transfection with control or PEA3 siRNA for 48 hours. PEA3 transcripts were significantly reduced (Figure 1A, left graph) as well as its known target gene MMP-9 (Figure 1C). Moreover, $H E Y-1$, a classic downstream target of the Notch signaling pathway, was also significantly reduced upon PEA3 knockdown. Taken together, these results suggest that PEA3 positively regulates Notch-1 and Notch-4 receptor expression and affects Notch activity in MDA-MB-231 cells.

\section{PEA3 regulates Notch-1 and Notch-4 expression in other subtypes of breast cancer}

Our investigations are the first to show that PEA3 is a transcriptional activator of Notch-1 and Notch-4 in MDAMB-231 breast cancer cells, an example of triple-negative breast cancer. We next assessed whether this is a common mechanism among the other subtypes of breast cancer cells. We used the single pool of PEA3 siRNAa because similar results were obtained for the two independent siRNA. MDA-MB-231 (triple-negative), MCF-7 (luminal A), BT474 (luminal B) and SKBr3 $\left(\mathrm{HER}^{+}\right)$cells were transfected with either scrambled or PEA3 siRNAa. Normalized to MDA-MB-231 cells, MCF-7 cells had slightly less PEA3 transcripts, followed by BT474 cells and then SKBr3 cells (Figure 2A). Notch-1 (Figure 2B) and Notch-4. (Figure 2C) transcript levels were compared with either scrambled or PEA3 siRNA among the cell lines. PEA3 regulation of Notch-1 was seen in MDA-MB-231, SKBr3 and MCF-7 cells, but not BT474 cells (Figure 2B). However, PEA3-mediated effects on Notch-4 transcripts were observed only in MDA-MB-231 cells (Figure 2C). This could be due in part to the fact that PEA3 basal transcript levels were very low in other cell types (Figure 2A). Motivated by this notion, we asked whether we could drive the expression of Notch-4 by increasing levels of PEA3 in breast cancer cells that express low endogenous PEA3 levels. To address this question, BT474 and SKBr3 cells were transfected with either pcDNA3.1 vector alone or PEA3-pcDNA3.1 expression plasmid. Notch-1 transcripts remained unchanged when PEA3 was overexpressed (Figures 2D and 2E). Notch-4 transcript levels were significantly increased ninefold in BT474 (Figure 2D) and sixteenfold in SKBr3 breast cancer cells (Figure 2E).

Taken together, PEA3 is required for Notch-1 transcription in at least three subtypes of breast cancer cells: MDA-MB-231, SKBr3 and MCF-7. However, PEA3 is an activator of Notch-4 transcription in MDA-MB-231 cells where endogenous PEA3 levels are high. Exogenous 


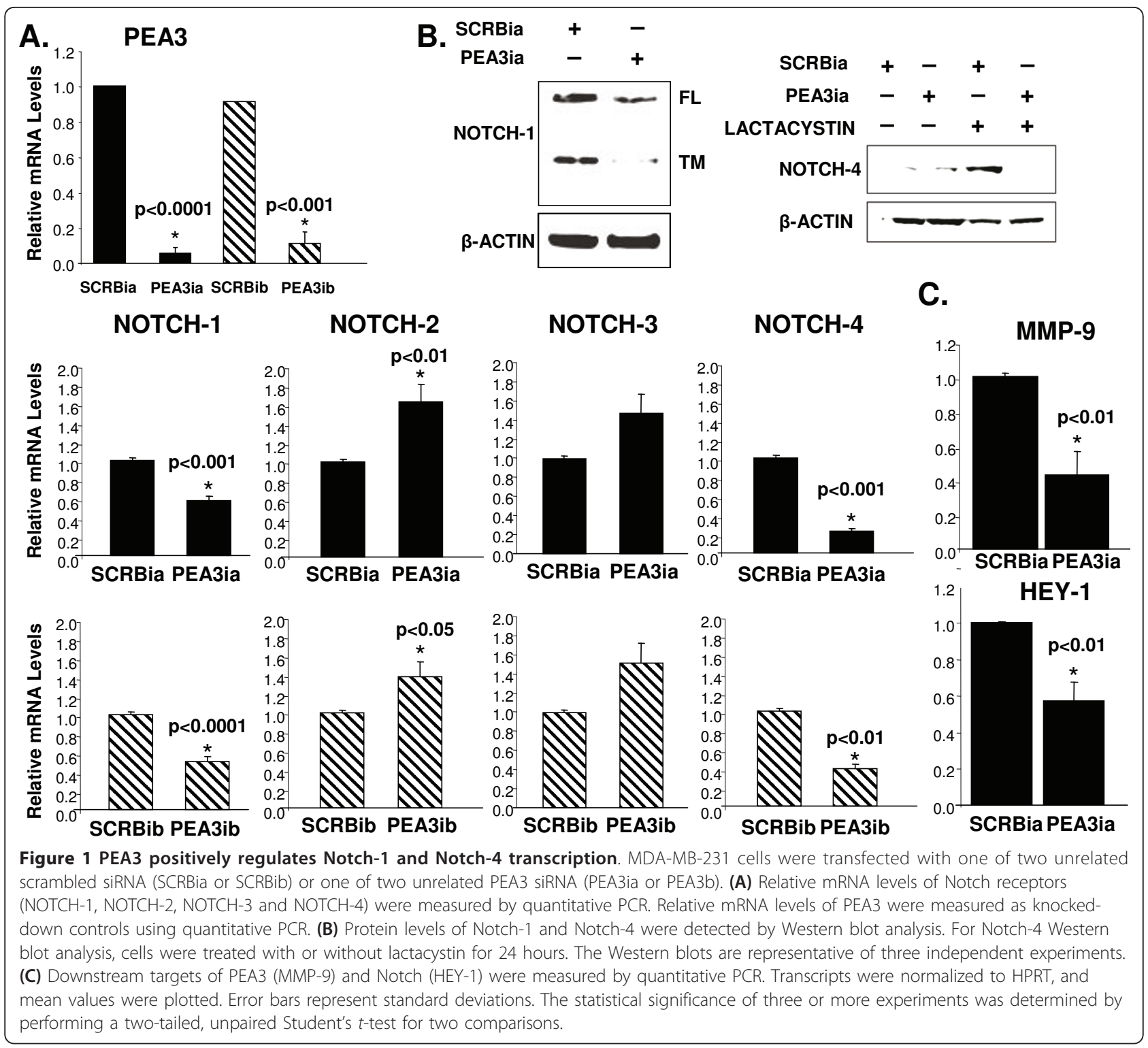

expression of PEA3 in BT474 and SKBr3 cells provides evidence that it is also a potential activator of Notch-4 transcription in other breast cancer subtypes.

PEA3 is enriched on the Notch- 1 and Notch-4 promoters

To determine the mechanism by which PEA3 regulates Notch-1 and Notch-4 transcription, we scanned the promoter regions of Notch-1 and Notch-4 using the National Center for Biotechnology Information Entrez GenBank $[59,60]$ and identified several ETS binding sites (Figures $3 \mathrm{~B}$ and $3 \mathrm{C}$, respectively). Interestingly, both promoters contained two AP-1 sites adjacent to ETS sites. A classic CBF-1 site was also previously identified in the Notch-4 promoter [23] and was used as a negative control for PEA3 recruitment. Primers were subsequently designed to include these identified regions. Primers flanking promoter regions containing no known consensus sites were used as negative controls. We then performed chromatin immunoprecipitation (ChIP) experiments on lysates from MDA-MB-231 cells that were transfected with either pcDNA3.1 vector alone or pcDNA3.1-PEA3 expression plasmid.

To confirm that PEA3 was overexpressed in MDAMB-231 cells, immunoprecipitation (IP) followed by Western blot analysis was performed to detect PEA3 protein (Figure 3A). The IP followed by Western blot analysis showed that endogenous PEA3 could not be detected in pcDNA3.1-transfected MDA-MB-231 cells. However, cells transfected with the PEA3 expression plasmid expressed PEA3 protein (Figure 3A). The ChIP 


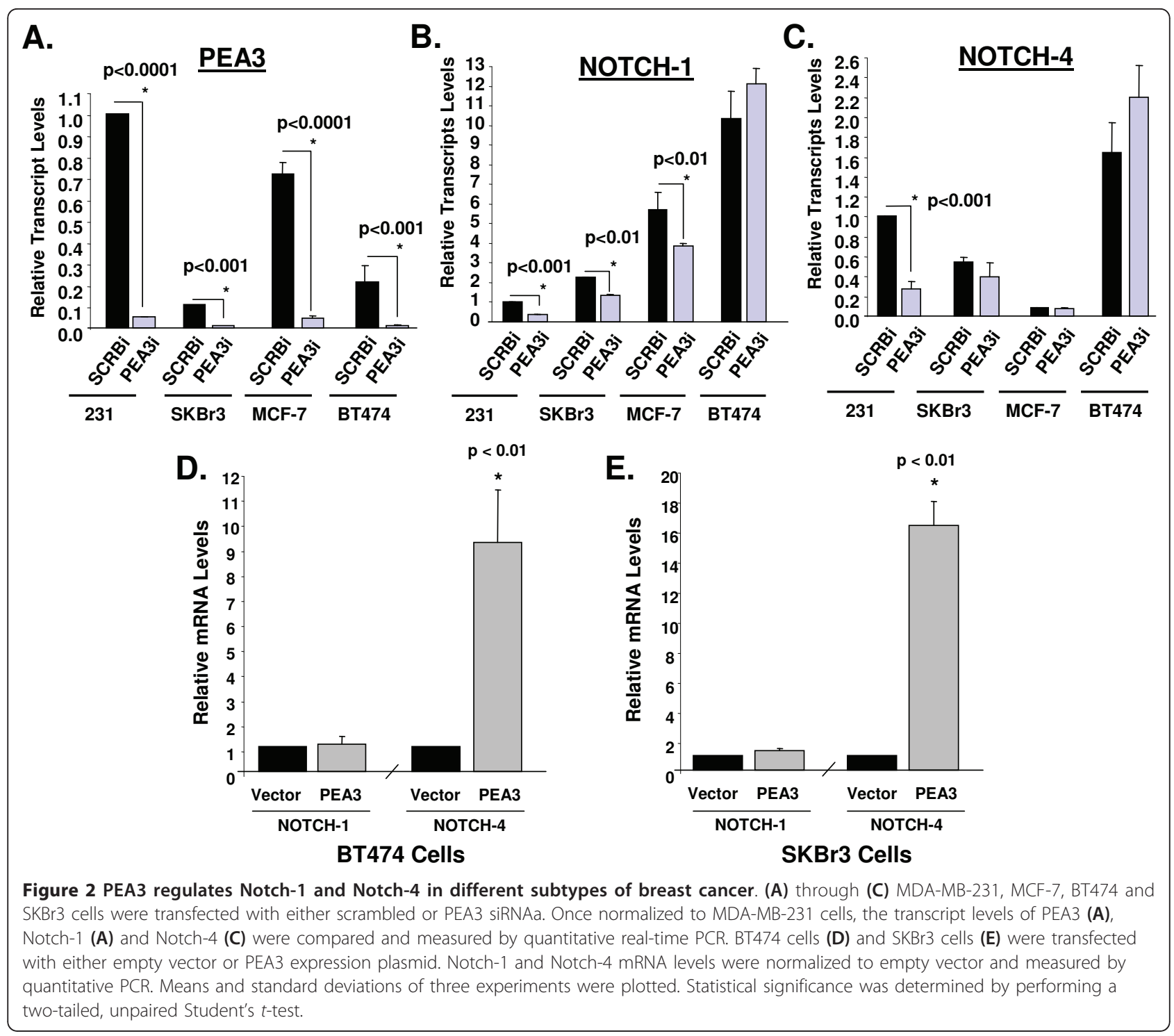

analysis was performed on cells transfected with vector alone or with $P E A 3$ expression plasmid (Figures $3 \mathrm{~B}$ and 3C). Endogenous PEA3 was not enriched in either the Notch-1 or Notch-4 promoter regions in cells transfected with pcDNA3.1. This could be due to weak antibody avidity or, more likely, could be a result of PEA3 protein instability [61]. PEA3 enrichment was found in both Notch-1 and Notch-4 promoter regions within $1 \mathrm{~kb}$ of the start site when PEA3 was overexpressed compared to vector alone-transfected cells (Figures $3 \mathrm{~B}$ and $3 \mathrm{C}$ ). A PEA3 siRNA smart pool was used to confirm the specificity of PEA3 recruitment and the PEA3 antibody. Figure 4A shows that PEA3 siRNA significantly decreased the enrichment of PEA3 in the identified promoter regions of Notch-1 and Notch-4 compared to a control siRNA. The Western blot shown in Figure $4 \mathrm{~B}$ confirms that the overexpressed PEA3 in MDA-MB-231 cells was almost completely knocked down using the PEA3 siRNAa smart pool.

To address whether PEA3 acts with AP-1 in Notch-1 and Notch-4 promoter regions, since it is known to work in accordance with c-Jun on several other genes $[34,35,50]$, transfected lysates with either phMB-vector or phMB-TAM-67, a dominant-negative form of c-Jun missing the transactivation domain [62], were subjected to ChIP analysis. PEA3 enrichment on the Notch-1 promoter was not affected by TAM-67 (Figure 5A). However, PEA3 recruitment to an ETS site adjacent to an AP-1 site approximately $70 \mathrm{nt}$ upstream from the start site of the Notch-4 promoter was significantly decreased by expression of TAM-67 (Figure 5B), indicating that the transactivation domain of c-Jun is required for PEA3 recruitment to the Notch-4 promoter. To confirm that TAM-67 reduces AP-1 transcriptional activity, an 


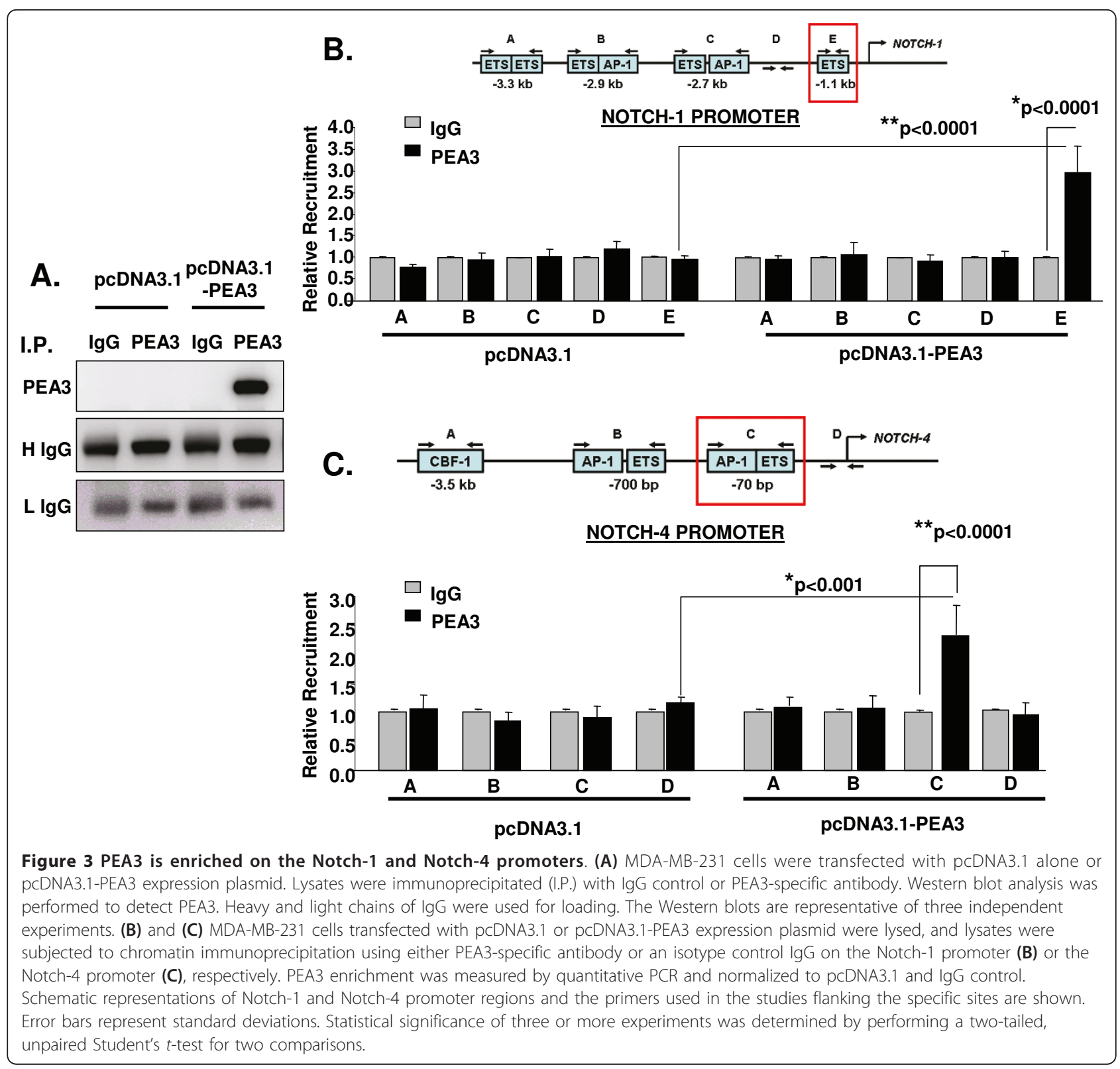

AP-1 luciferase reporter assay was performed in MDAMB-231 cells transfected with either phMB vector alone or phMB-TAM-67. The results showed that the TAM67-transfected cells contained more than $50 \%$ less AP-1 reporter activity than vector alone-transfected cells (Figure 5). To determine whether c-Jun specifically is required for PEA3 enrichment in the identified Notch-4 promoter region, transfected lysates with either control or c-Jun siRNA smart pool were subjected to ChIP analysis. In agreement with our previous findings, PEA3 enrichment in the Notch-4 promoter region was significantly decreased upon knockdown of c-Jun (Figure 5B), suggesting that $\mathrm{c}-J$ un is required for PEA3 enrichment in the identified Notch-4 promoter region. We confirmed that c-Jun protein was knocked down by siRNA on the basis of Western blot analysis (Figure 5B). We also confirmed that c-Jun protein was in a complex with PEA3 in MDA-MB-231 nuclear extract by performing a co-IP assay (Figure 5C).

To assess whether the results of the ChIP studies were not due to artificial interactions as a result of PEA3 overexpression, we performed a Notch-4 luciferase reporter assay using a minimal promoter region $(-650$ to +1$)$ which contains the same AP-1/ETS region just $-70 \mathrm{nt}$ upstream from the start site. The wild-type construct contained an intact AP-1 and ETS consensus site at - 70 nt. The mutant AP-1 construct contained an ablated AP-1 consensus site, but the adjacent ETS binding site was preserved [32]. 


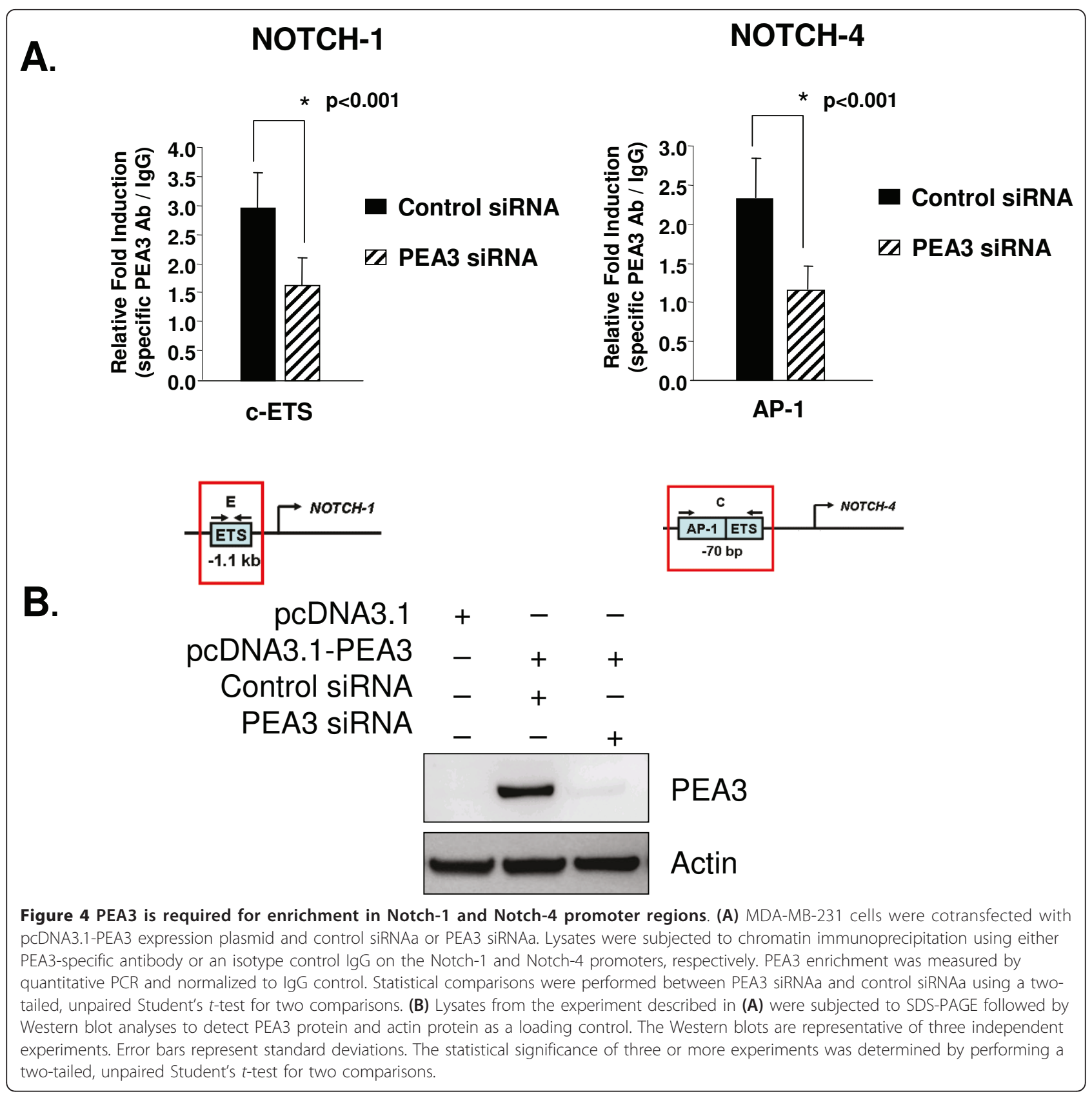

Knockdown of endogenous PEA3 using siRNA significantly decreased wild-type AP-1-containing reporter activity (Figure 6, right graph) or mutant AP-1-containing reporter activity (Figure 6, inset) compared to the scrambled control. These results suggest that both PEA3 andAP- 1 are critical for the regulation of the -70 nt region within the Notch-4 promoter in MBA-MD-231 cells. As a control study, we observed no significant difference in AP1 luciferase reporter activity upon PEA3 knockdown, indicating that PEA3 was not mediating effects on the Notch-4 promoter indirectly through AP-1 regulation (Figure 6, left graph). Herein we provide the first evidence that both
PEA3 and c-Jun are required to activate the Notch-4 promoter.

\section{Differential regulation of Notch-4 by AP- 1 members}

To determine which members of the Fos family of transcription factors are required for Notch-4 transcription, we performed real-time PCR to detect Notch-4 transcripts in response to knockdown of Fra-1 and c-FOS, which are the major forms of Fos in MDA-MB-231 cells. The results showed that Notch- 4 transcripts were decreased 2.5-fold when Fra-1 was knocked down similarly to PEA3 or c-JUN knockdown (Figure 7A, upper 


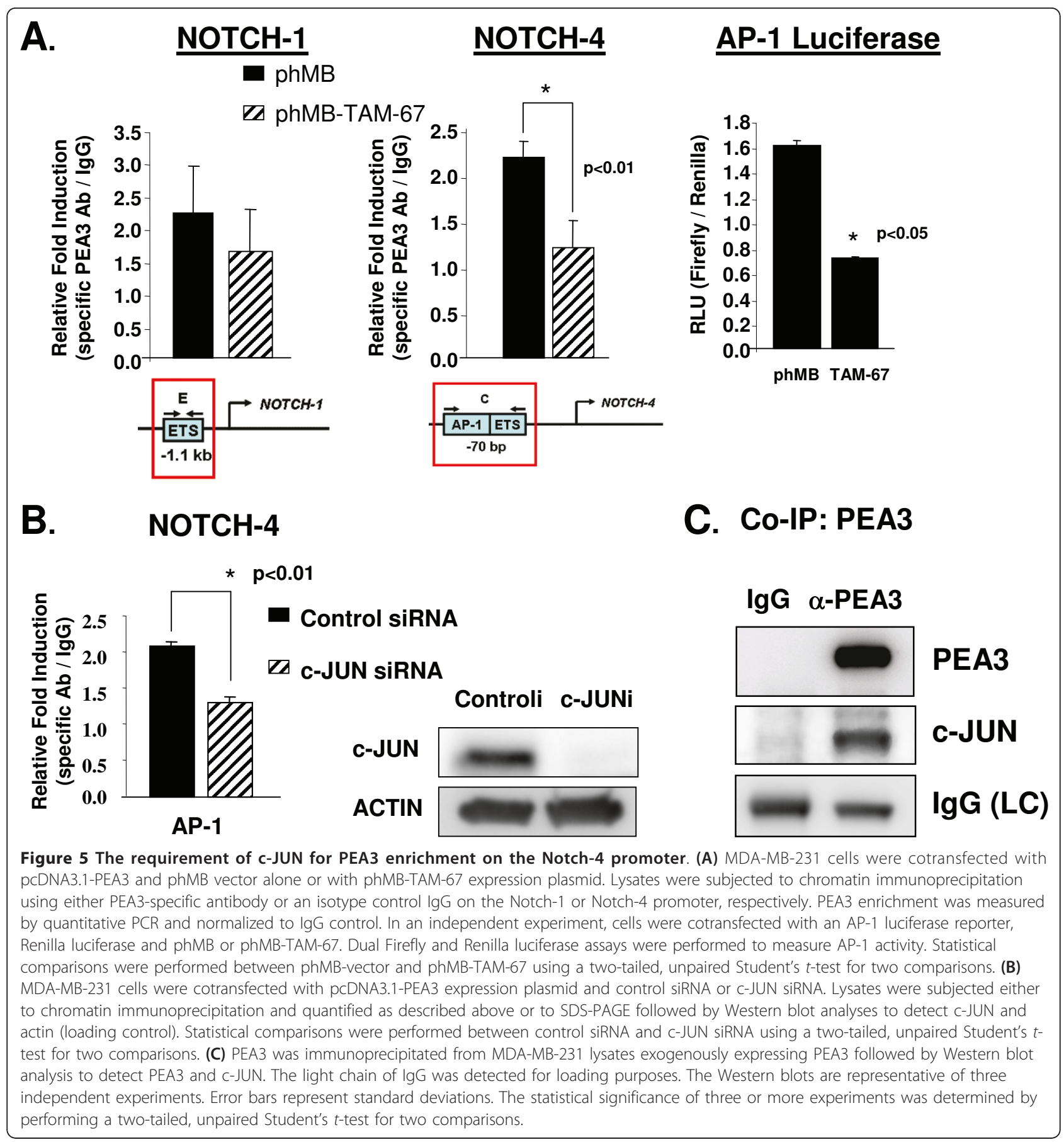

graph). Conversely, c-FOS siRNA increased Notch-4 transcripts twofold compared to a scrambled control siRNA (Figure 7A, lower graph). Figure 7B demonstrates the efficacy of knockdown by PEA3, c-Jun, Fra-1 and cFOS siRNA as measured by real-time PCR and Western blot analysis. These results, together with those of the previous ChIP studies, suggest that PEA3 regulates Notch-4 transcription by potentially interacting with c-
Jun and Fra-1. The results also indicate that c-FOS is a potential transcriptional repressor of Notch-4.

Dual inhibition of Notch and PEA3 inhibits cell proliferation and induces apoptosis

Notch is vital for proliferation and cell fate determination [63], whereas PEA3 is critical for cell migration and invasion $[64,65]$. Both aberrant and unregulated 


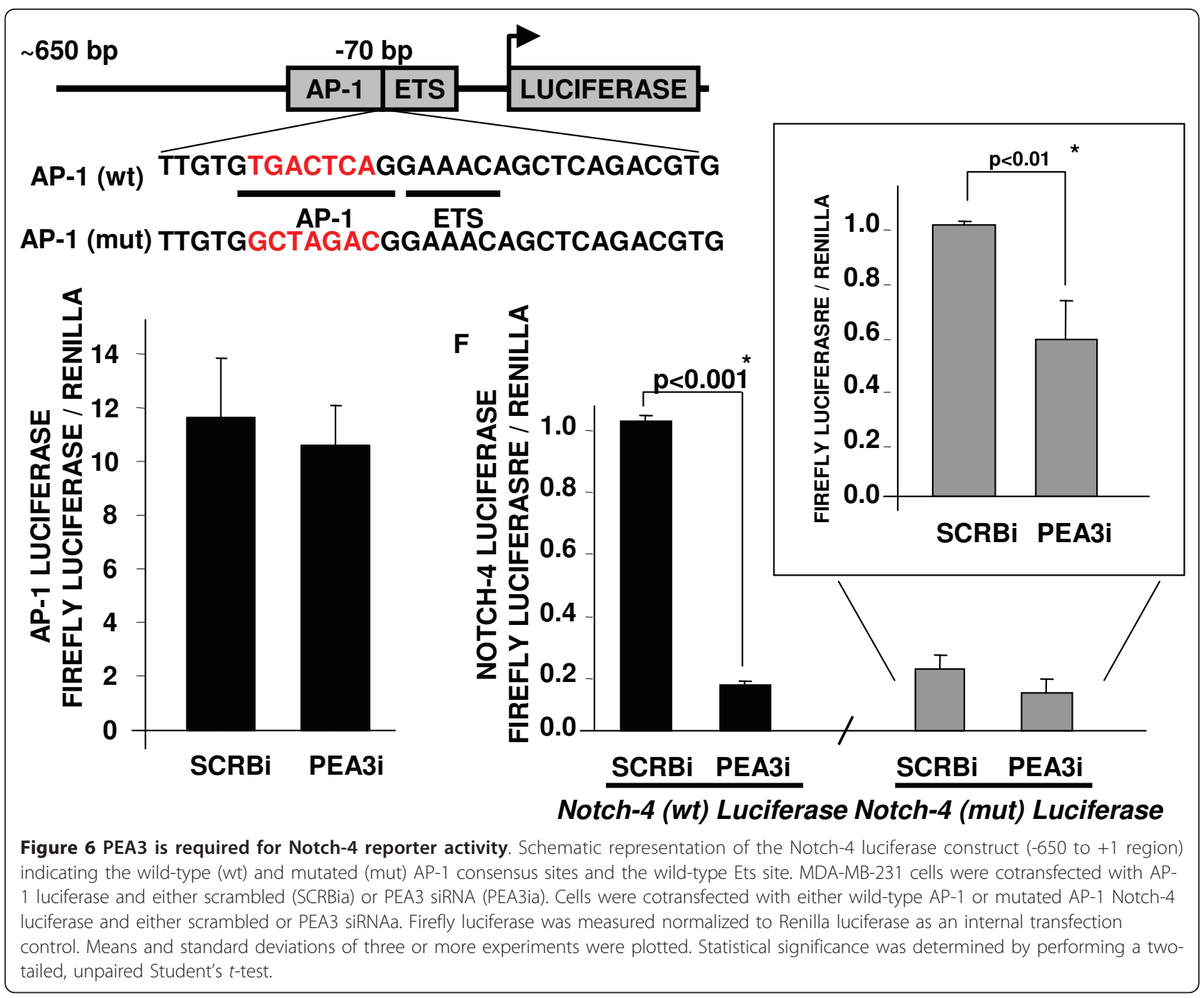

activities can lead to overall malignancy and poor survival $[25,40]$. To understand their biological significance and their effect in MDA-MB-231 triple-negative cells, we explored dual inhibition of PEA3 and Notch using the specific PEA3 siRNA smart pool and the preclinical MRK-003 GSI, respectively. MDA-MB-231 cells were transfected with scrambled control or PEA3 siRNA alone, treated with vehicle or MRK-003 GSI, or a combination of PEA3 siRNA plus MRK-003 GSI thereof for 48 hours. Independently, PEA3 knockdown or Notch inhibition had little effect on the cell cycle compared to control (Figure 8A). PEA3 knockdown or MRK-003 GSI treatment of MDA-MB-231 cells alone showed a modest but not significant increase in $G_{1}$ phase arrest, a modest decrease in the $S$ phase and little effect on the $G_{2} / M$ phase (Figure 8A). However, the combination of PEA3 knockdown and MRK-003 GSI treatment resulted in a significant increase in the $\mathrm{G}_{1}$ phase compared to control $(P<0.05)$ (Figure 8A). In the presence of both PEA3 knockdown and MRK-003 GSI treatment, there was a significant reduction in the $S$ phase of the cell cycle compared to control $(P<0.05)$. Also, both PEA3 knockdown and MRK-003 GSI treatment resulted in a significant reduction in the $\mathrm{G}_{2} / \mathrm{M}$ phase of the cell cycle compared to control $(P<0.05)$ (Figure 8A). These results indicate that both PEA3 and Notch are critical for the proliferation of MDA-MB-231 cells.

We then asked whether dual inhibition using both PEA3 knockdown and Notch inhibition affect cell viability, potentially through increased apoptosis. Independently, PEA3 knockdown showed no change in apoptosis as measured by (1) annexin V staining (Figure $8 \mathrm{~B}$ ) or (2) cell viability using trypan blue exclusion (Figure 8C). MRK-003 GSI treatment alone increased apoptosis to 30\% (Figure $8 \mathrm{~B}$ ) and decreased cell viability to $60 \%$ (Figure $8 \mathrm{C}$ ). Importantly, the combination of PEA3 knockdown and MRK003 GSI treatment significantly increased apoptosis to almost $40 \%$ as measured by positive staining of annexin $\mathrm{V}$ 


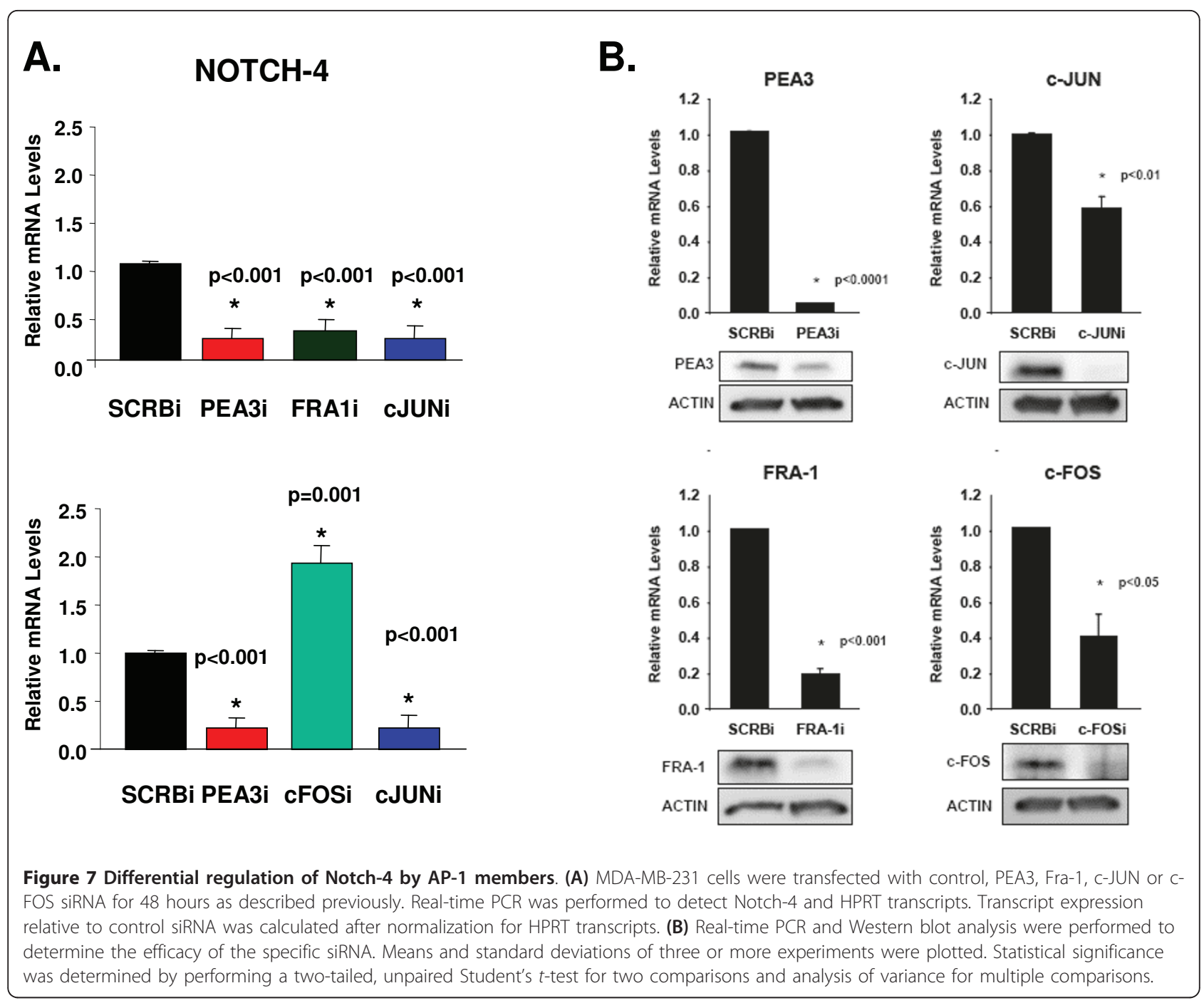

cells (Figure $8 \mathrm{~B}$ ) and diminished cell viability to $50 \%$ (Figure $8 \mathrm{C}$ ). These results, taken together with the cell cycle data, indicate that both PEA3 and Notch activities are critical for cell proliferation and survival in MDA-MB-231 breast cancer cells.

\section{Dual inhibition of Notch and PEA3 inhibits anchorage- independent growth}

To address whether dual inhibition of PEA3 and Notch activities affect anchorage-independent growth as an in vitro measure of tumorigenicity, we performed a colony formation assay with MDA-MB-231 cells that were transfected with either scrambled control or PEA3 siRNA and treated with vehicle or MRK-003 GSI independently or in combination. We observed a reduction of almost $55 \%$ in the number of colonies when PEA3 was knocked down or $61 \%$ when Notch was inhibited using a GSI in cells compared to vehicle + control siRNA control (Figures 9A and 9B). Furthermore, the number of colonies was reduced further to $20 \%$ upon PEA3 knockdown and GSI treatment compared to vehicle + control siRNA (Figures 9A and 9B).

Tumor growth of MDA-MB-231 xenografts is dependent on PEA3 or Notch activity

The results so far have indicated that dual inhibition of PEA3 and Notch signaling inhibits both anchorage-dependent and anchorage-independent cell growth in vitro more effectively than either treatment alone. The results from the anchorage-independent assay suggest that transient knockdown of PEA3 using siRNA is sufficient to inhibit the formation of colonies for up to two weeks. On the basis of these results, we asked whether transient knockdown of PEA3 could inhibit tumor formation in vivo and whether treatment with MRK-003 GSI in combination could prevent tumor formation. We performed an orthotopic MDA-MB-231 tumor xenograft study in athymic mice. MDA-MB-231 cells were transfected with control or 

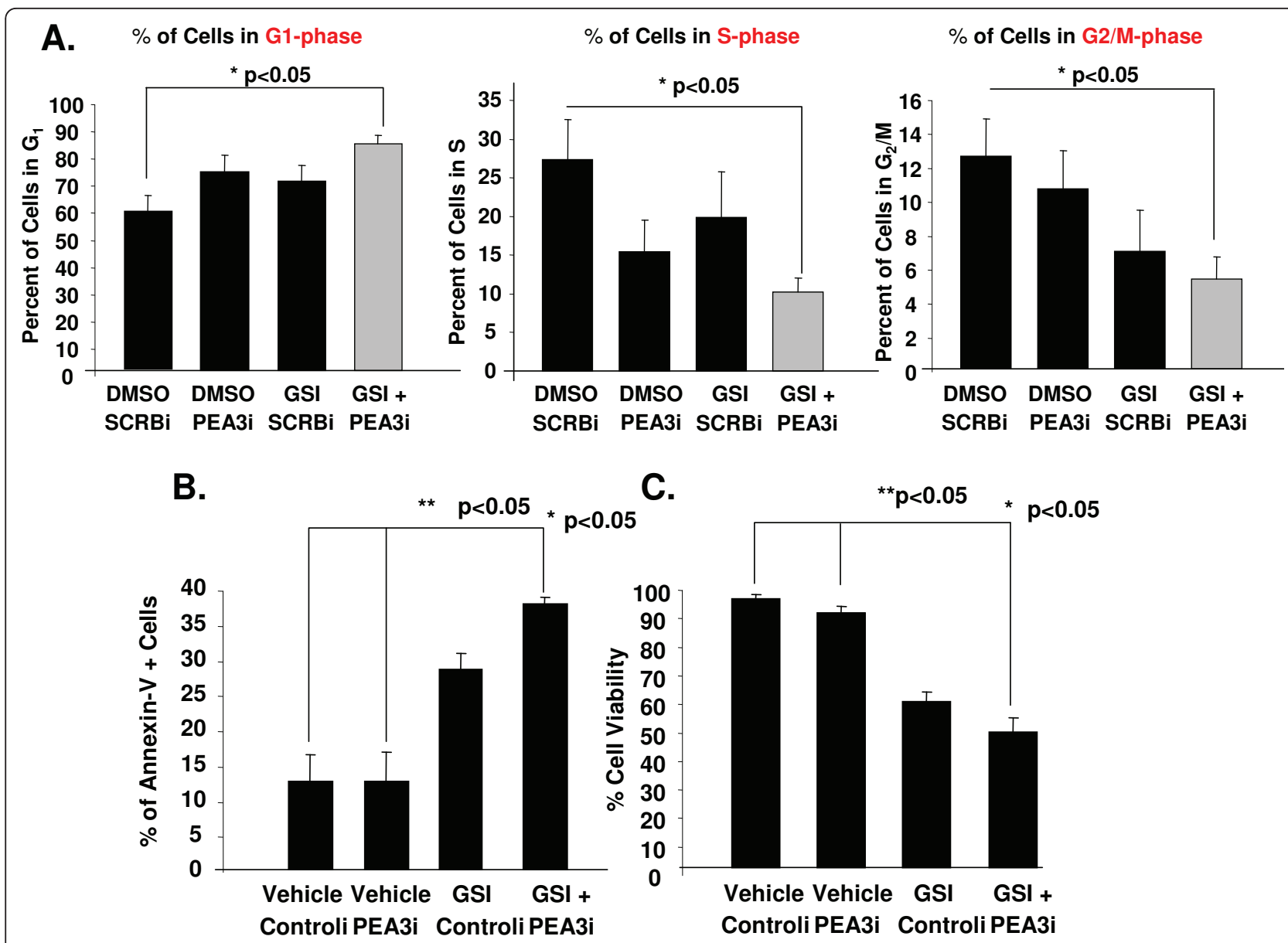

Figure 8 Dual inhibition of Notch and PEA3 inhibits cell proliferation and induces apoptosis. MDA-MB-231 cells were transfected with scrambled or PEA3 siRNA alone or were treated with vehicle (DMSO) or a $\gamma$-secretase inhibitor (MRK-003 GSI), or a combination thereof, for 48 hours. Cell cycle analysis (A) and annexin $\vee$ staining (B) were performed by using flow cytometry. (C) Percentages of viable cells were measured by the trypan blue exclusion method using a standard light microscope ( $\times 10$ original magnification). The mean percentage and standard deviation of cells in each experiment were plotted. Statistical significance was determined by performing analysis of variance for multiple comparisons. The error bars represent standard deviations of the mean for three independent experiments.

PEA3 siRNA in vitro (Figure 9D) and then injected into the mammary fat pads of female athymic mice. The mice were randomized to injection with vehicle control or MRK-003 GSI. The results showed that either PEA3 knockdown or GSI treatment significantly reduced tumor growth by almost similar rates compared to vehicle + scrambled control siRNA (Figure 9C).

We have shown for the first time, to our knowledge, that PEA3 is a novel activator of Notch-1 and Notch-4 transcription in different subtypes of breast cancer cells and could prove to be an important therapeutic target, possibly upstream of Notch-1 and/or Notch-4 signaling.

\section{Discussion}

PEA3 was originally identified as a member of the ETS family of transcription factors. Since then, it has been observed that PEA3 is expressed during normal breast development, is quickly lost upon maturation and yet reemerges in metastatic breast cancers [33,54,61,66-68]. Similarly, Notch has been implicated in breast cancer, demonstrating elevated expression and activity in breast tumors [25,26]. Little is known about the factors that influence Notch gene expression and why its levels are elevated in breast cancer. Herein we provide the first evidence of transcriptional regulation of Notch-1 and Notch4 by PEA3 in MDA-MB-231 and other breast cancer subtypes (Figures 1 through 3 ). We have demonstrated that Notch-4 gene regulation is dependent on AP-1 factors such as c-Jun, Fra-1, c-Fos and now PEA3, depending on cellular context (Figures 5 and 7). Interestingly, we provide evidence that c-Jun and Fra-1 are transcriptional activators of Notch-4, but that c-FOS could be a transcriptional repressor of Notch-4 (Figure 7). PEA3 regulates the Notch-1 promoter, but the additional factors 


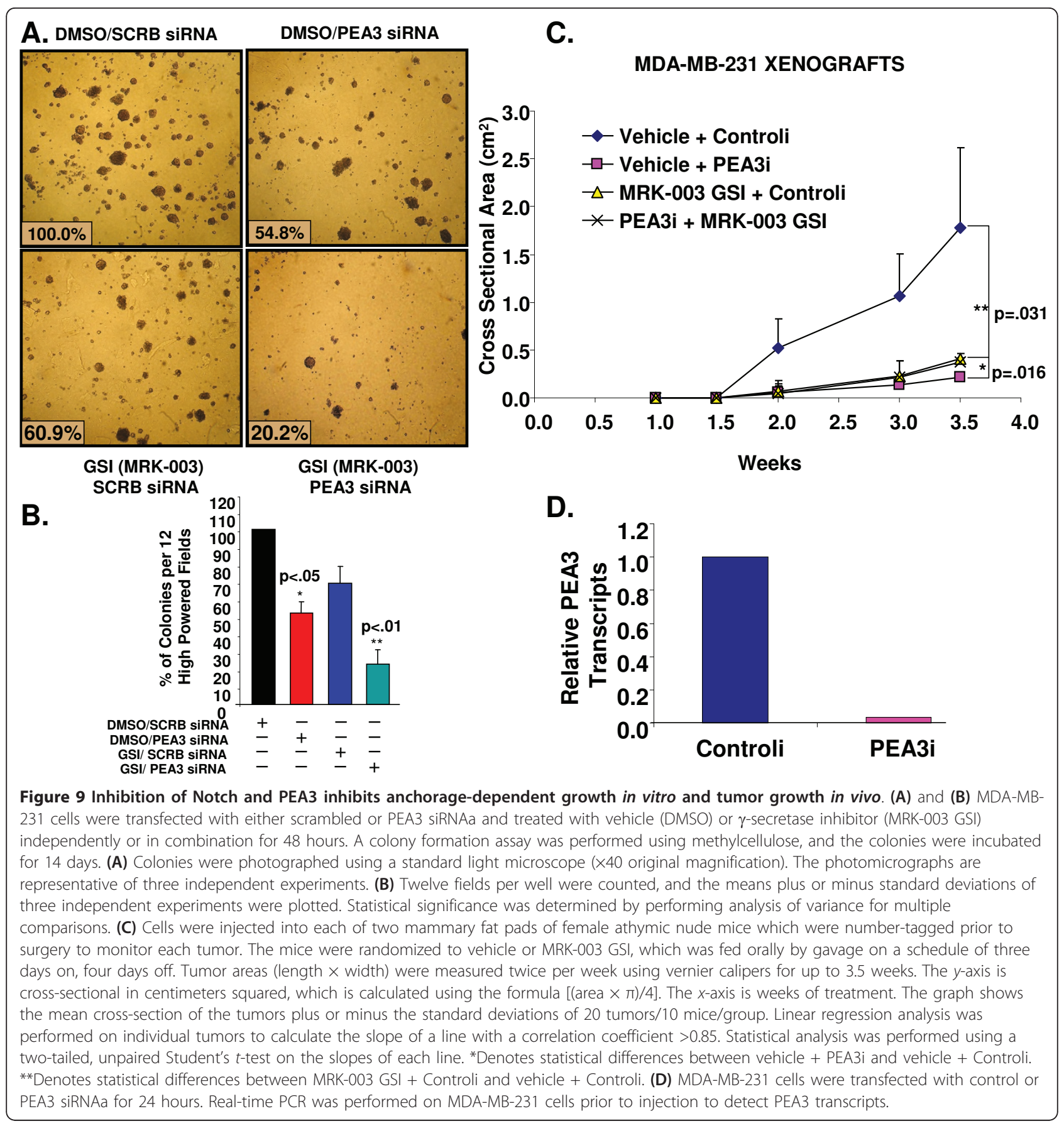

that aid in that regulation are still being investigated. Further evidence reveals that PEA3 inhibition helps sensitize MDA-MB-231 cells to a GSI, showing promise in significantly reducing both anchorage-dependent and anchorage-independent growth as well as increasing apoptosis in vitro (Figures 8, 9A and 9B). Moreover, PEA3 expression or Notch activity is required for optimal growth of MDA-MB-231 tumors in vivo (Figure 9C). Thus, PEA3 emerges as a potential target, possibly upstream of Notch activity, for triple-negative cancer and possibly other breast cancer subtypes where PEA3 and/or Notch activities are critical for growth. This was evident in the preclinical model of our MDA-MB-231 xenograft study (Figure 9C). Either PEA3 knockdown or GSI treatment was adequate to significantly inhibit tumor growth in vivo. This result could suggest that targeting PEA3, a transcriptional activator of Notch-1 and Notch-4, hits multiple targets at once. For example, PEA3 is an 
activator of MMPs [36-39,53], uPAR [55,56], COX-2 [35] and now Notch-1 and Notch-4. PEA3 expression and Notch signaling could be critical for tumor formation and communication with the tumor microenvironment, which is not possible to recapitulate in vitro using singlecell suspensions. The severe side effects associated with GSI treatment, such as gastrointestinal toxicity [69,70], could possibly be avoided if inhibition of PEA3 is able to inhibit several growth- and metastasis-promoting signaling pathways.

Notch is a cellular fate determinant and can induce cell proliferation and/or differentiation, depending on the cellular environment [71]. PEA3 has been linked to the invasion, migration and aggressiveness of tumor cells $[33,40,53,54,57,61,67,68,72,73]$. The dual or individual inhibition of Notch by the GSI, and the inhibition of PEA3 by siRNA, acts by preventing two vital arms of cancer progression, namely, growth and possibly invasion, which we are currently investigating in vitro and in vivo. Emerging nanotechnology can be used as a means by which to direct siRNA therapies [74], and the advent of stapled interface peptides [75] that disrupt transcription factor complexes transforms the notion of specific targeting of the PEA3 transcription factor into a potential reality.

In addition, Harrison et al. [27] implicated Notch-4 in mammary tumor stem cell survival and self-renewal in a recent study in which they demonstrated that targeting Notch-4 specifically was more effective than a targeting a GSI in inhibiting the Notch pathway. In our studies, we found that Notch-4 gene transcription was more sensitive to PEA3 inhibition. Given this fact, the sensitivity that we obtained in our MDA-MD-231 system by the dual inhibition using a PEA3 siRNA in combination with MRK-003 GSI reduced viability and increased apoptosis may be explained by the notion that we may have targeted not only the proliferation and survival of bulk cancer cell populations but also possibly the cancer stem cell population.

Herein we have provided evidence of a novel therapeutic strategy to be exploited for the treatment of triple-negative breast cancer and potentially other breast cancer subtypes where PEA3 regulates Notch-1 and Notch-4. Enhanced sensitivity toward current GSIs or alternative strategies for future clinical trials by inhibition of PEA3 by nanoparticles, small-molecule inhibitors or future siRNA approaches may increase patient response to treatment and could reduce or eliminate recurrence if stem cell populations are eliminated. Inhibiting PEA3 may also allow for a larger therapeutic window for GSI treatment, enabling the reduction of pharmacological doses or possibly eliminating the need for the GSI if PEA3 is indeed upstream of Notch signaling, thus lowering resultant undesirable side effects such as gastrointestinal toxicity and possibly skin cancer.

\section{Conclusions}

Taken together, the results from this study demonstrate for the first time that Notch-1 and Notch-4 are novel transcriptional targets of PEA3 in breast cancer cells. PEA3 emerges as a potential innovative target upstream from Notch activity for triple-negative cancer and possibly other breast cancer subtypes where PEA3 and/or Notch activities are critical for growth and aggressive phenotypes. The significance of targeting of PEA3 and/ or Notch pathways allows a potentially novel therapeutic strategy for the treatment of breast cancers.

\section{Abbreviations}

AP-1: activator protein 1; DMEM: Dulbecco's modified Eagle's medium; ERa: estrogen receptor $a$; GSI: $\gamma$-secretase inhibitor; IL: interleukin; MMP: matrix metalloprotease; NEC: extracellular notch; NFkB: nuclear factor KB; NIC: intracellular notch; NTM: transmembrane notch; PBS: phosphate-buffered saline; PCR: polymerase chain reaction; PEA3: polyomavirus enhancer activator 3; SCRBi: scrambled control siRNA; siRNA: small interfering RNA;

\section{Acknowledgements}

We thank Drs Richard Schultz, Maurizio Bocchetta and Paola Rizzo at Loyola University Medical Center for helpful discussions and suggestions throughout this work. The authors express much gratitude for the support provided by US Department of Defense Idea award W81XWH-08-1-0643 BC074462 (to CO)

\section{Author details}

${ }^{1}$ Molecular and Cellular Biochemistry Program, Loyola University Medical Center, Maywood, IL 60153, USA. ${ }^{2}$ Molecular Biology Program, Loyola University Medical Center, 2160 S. First Ave, Maywood, IL 60153, USA. ${ }^{3}$ Cancer Institute of the University of Mississippi Medical Center, $2500 \mathrm{~N}$. State St, Jackson, MS 39216, USA. ${ }^{4}$ Oncology Institute, Loyola University Medical Center, 2160 S. First Ave, Maywood, IL 60153, USA. ${ }^{5}$ Department of Pathology, Loyola University Medical Center, 2160 S. First Ave, Maywood, IL 60153, USA. ${ }^{6}$ Department of Microbiology and Immunology, Loyola University Medical Center, 2160 S. First Ave, Maywood, IL 60153, USA.

\section{Authors' contributions}

AGC performed the majority of the experiments and wrote the manuscript. AR and KP injected MDA-MB-231 cells into mice, fed mice MRK-003 orally by gavage and assisted in tumor area measurements and statistical calculations. LM is a co-principal investigator on CO's US Department of Defense award and provided reagents and critical expertise. All authors read and approved the final manuscript.

\section{Competing interests}

AGC and CO declare that there is a patent pending on the identification of PEA3 as a biomarker for sensitivity to GSIs in breast tumors and possibly other solid tumors in conjunction with work conducted with the MRK-003 GSI developed by Merck Oncology International, Inc. We declare that there are no other financial conflicts of interest besides the patent application.

Received: 21 January 2011 Revised: 3 May 2011

Accepted: 14 June 2011 Published: 14 June 2011

\section{References}

1. Sotiriou C, Neo SY, MCShane LM, Korn EL, Long PM, Jazaeri A, Martiat P, Fox SB, Harris AL, Liu ET: Breast cancer classification and prognosis based on gene expression profiles from a population-based study. Proc Natl Acad Sci USA 2003, 100:10393-10398. 
2. Sotiriou C, Pusztai L: Gene-expression signatures in breast cancer. N Engl J Med 2009, 360:790-800.

3. Slamon DJ, Leyland-Jones B, Shak S, Fuchs H, Paton V, Bajamonde A, Fleming T, Eiermann W, Wolter J, Pegram M, Baselga J, Norton L: Use of chemotherapy plus a monoclonal antibody against HER2 for metastatic breast cancer that overexpresses HER2. N EnglJ Med 2001, 344:783-792.

4. Reis-Filho JS, Tutt AN: Triple negative tumours: a critical review. Histopathology 2008, 52:108-118.

5. Weigelt B, Baehner FL, Reis-Filho JS: The contribution of gene expression profiling to breast cancer classification, prognostication and prediction: a retrospective of the last decade. J Pathol 2010, 220:263-280.

6. Miele L: Rational targeting of Notch signaling in breast cancer. Expert Rev Anticancer Ther 2008, 8:1197-1202.

7. Blaumueller CM, Artavanis-Tsakonas S: Comparative aspects of Notch signaling in lower and higher eukaryotes. Perspect Dev Neurobiol 1997, 4:325-343.

8. Dunwoodie SL, Henrique D, Harrison SM, Beddington RS: Mouse DII3: a novel divergent Delta gene which may complement the function of other Delta homologues during early pattern formation in the mouse embryo. Development 1997, 124:3065-3076.

9. Lindsell CE, Shawber CJ, Boulter J, Weinmaster G: Jagged: a mammalian ligand that activates Notch1. Cell 1995, 80:909-917.

10. Shawber C, Boulter J, Lindsell CE, Weinmaster G: Jagged2: a serrate-like gene expressed during rat embryogenesis. Dev Biol 1996, 180:370-376.

11. Callahan R, Raafat A: Notch signaling in mammary gland tumorigenesis. J Mammary Gland Biol Neoplasia 2001, 6:23-36.

12. Brou C, Logeat F, Gupta N, Bessia C, LeBail O, Doedens JR, Cumano A, Roux P, Black RA, Israël A: A novel proteolytic cleavage involved in Notch signaling: the role of the disintegrin-metalloprotease TACE. Mo/ Cell 2000, 5:207-216.

13. Saxena MT, Schroeter EH, Mumm JS, Kopan R: Murine notch homologs (N1-4) undergo presenilin-dependent proteolysis. J Biol Chem 2001, 276:40268-40273.

14. Hsieh JJ, Zhou S, Chen L, Young DB, Hayward SD: CIR, a corepressor linking the DNA binding factor CBF1 to the histone deacetylase complex. Proc Natl Acad Sci USA 1999, 96:23-28.

15. Wu L, Aster JC, Blacklow SC, Lake R, Artavanis-Tsakonas S, Griffin JD: MAML1, a human homologue of Drosophila Mastermind, is a transcriptional co-activator for NOTCH receptors. Nat Genet 2000, 26:484-489

16. Maier MM, Gessler M: Comparative analysis of the human and mouse Hey1 promoter: Hey genes are new Notch target genes. Biochem Biophys Res Commun 2000, 275:652-660.

17. Ronchini C, Capobianco AJ: Induction of cyclin D1 transcription and CDK2 activity by Notch ${ }^{\text {ic }}$ implication for cell cycle disruption in transformation by Notch ${ }^{i c}$. Mol Cell Biol 2001, 21:5925-5934.

18. Weng AP, Millholland JM, Yashiro-Ohtani Y, Arcangeli ML, Lau A, Wai C, del Bianco C, Rodriguez CG, Sai H, Tobias J, Li Y, Wolfe MS, Shachaf C, Felsher D, Blacklow SC, Pear WS, Aster JC: c-Myc is an important direct target of Notch1 in T-cell acute lymphoblastic leukemia/lymphoma. Genes Dev 2006, 20:2096-2109.

19. Efferson CL, Winkelmann CT, Ware C, Sullivan T, Giampaoli S, Tammam J, Patel S, Mesiti G, Reilly JF, Gibson RE, Buser C, Yeatman T, Coppola D, Winter C, Clark EA, Draetta GF, Strack PR, Majumder PK: Downregulation of Notch pathway by a $\gamma$-secretase inhibitor attenuates AKT/mammalian target of rapamycin signaling and glucose uptake in an ERBB2 transgenic breast cancer model. Cancer Res 2010, 70:2476-2484.

20. Magnifico A, Albano L, Campaner S, Delia D, Castiglioni F, Gasparini P, Sozzi G, Fontanella E, Menard S, Tagliabue E: Tumor-initiating cells of HER2-positive carcinoma cell lines express the highest oncoprotein levels and are sensitive to trastuzumab. Clin Cancer Res 2009, 15:2010-2021.

21. Osipo C, Patel P, Rizzo P, Clementz AG, Hao L, Golde TE, Miele L: ErbB-2 inhibition activates Notch-1 and sensitizes breast cancer cells to a $\gamma$ secretase inhibitor. Oncogene 2008, 27:5019-5032.

22. Watters JW, Cheng C, Majumder PK, Wang R, Yalavarthi S, Meeske C, Kong L, Sun W, Lin J, Heyer J, Ware C, Winter C, Reilly JF, Demuth T, Clark S, Chiu Ml, Robinson MO, Kohl N, Kannan K: De novo discovery of a $\gamma^{-}$ secretase inhibitor response signature using a novel in vivo breast tumor model. Cancer Res 2009, 69:8949-8957.
23. Rizzo P, Miao H, D'Souza G, Osipo C, Song LL, Yun J, Zhao H, Mascarenhas J, Wyatt D, Antico G, Hao L, Yao K, Rajan P, Hicks C, Siziopikou K, Selvaggi S, Bashir A, Bhandari D, Marchese A, Lendahl U, Qin JZ, Tonetti DA, Albain K, Nickoloff BJ, Miele L: Cross-talk between notch and the estrogen receptor in breast cancer suggests novel therapeutic approaches. Cancer Res 2008, 68:5226-5235.

24. Dickson BC, Mulligan AM, Zhang H, Lockwood G, O'Malley FP, Egan SE, Reedijk M: High-level JAG1 mRNA and protein predict poor outcome in breast cancer. Mod Pathol 2007, 20:685-693.

25. Reedijk M, Odorcic S, Chang L, Zhang H, Miller N, McCready DR, Lockwood G, Egan SE: High-level coexpression of JAG1 and NOTCH1 is observed in human breast cancer and is associated with poor overall survival. Cancer Res 2005, 65:8530-8537.

26. Reedijk M, Pinnaduwage D, Dickson BC, Mulligan AM, Zhang H, Bull SB, O'Malley FP, Egan SE, Andrulis IL: JAG1 expression is associated with a basal phenotype and recurrence in lymph node-negative breast cancer. Breast Cancer Res Treat 2008, 111:439-448.

27. Harrison H, Farnie G, Howell SJ, Rock RE, Stylianou S, Brennan KR, Bundred NJ, Clarke RB: Regulation of breast cancer stem cell activity by signaling through the Notch4 receptor. Cancer Res 2010, 70:709-718.

28. Hu C, Diévart A, Lupien M, Calvo E, Tremblay G, Jolicoeur P: Overexpression of activated murine Notch1 and Notch3 in transgenic mice blocks mammary gland development and induces mammary tumors. Am J Pathol 2006, 168:973-990.

29. Yamaguchi N, Oyama T, Ito E, Satoh H, Azuma S, Hayashi M, Shimizu K, Honma R, Yanagisawa Y, Nishikawa A, Kawamura M, Imai J, Ohwada S, Tatsuta K, Inoue J, Semba K, Watanabe S: NOTCH3 signaling pathway plays crucial roles in the proliferation of ErbB2-negative human breast cancer cells. Cancer Res 2008, 68:1881-1888.

30. O'Neill CF, Urs S, Cinelli C, Lincoln A, Nadeau RJ, León R, Toher J, MoutaBellum C, Friesel RE, Liaw L: Notch2 signaling induces apoptosis and inhibits human MDA-MB-231 xenograft growth. Am J Pathol 2007, 171:1023-1036.

31. Alimirah F, Panchanathan R, Davis FJ, Chen J, Choubey D: Restoration of p53 expression in human cancer cell lines upregulates the expression of Notch1: implications for cancer cell fate determination after genotoxic stress. Neoplasia 2007, 9:427-434.

32. Wu J, Iwata F, Grass JA, Osborne CS, Elnitski L, Fraser P, Ohneda O, Yamamoto M, Bresnick EH: Molecular determinants of NOTCH4 transcription in vascular endothelium. Mol Cell Biol 2005, 25:1458-1474.

33. Trimble MS, Xin JH, Guy CT, Muller WJ, Hassell JA: PEA3 is overexpressed in mouse metastatic mammary adenocarcinomas. Oncogene 1993, 8:3037-3042.

34. Iguchi A, Kitajima I, Yamakuchi M, Ueno S, Aikou T, Kubo T, Matsushima K, Mukaida N, Maruyama I: PEA3 and AP-1 are required for constitutive IL-8 gene expression in hepatoma cells. Biochem Biophys Res Commun 2000, 279:166-171.

35. Subbaramaiah K, Norton L, Gerald W, Dannenberg AJ: Cyclooxygenase-2 is overexpressed in HER-2/neu-positive breast cancer: evidence for involvement of AP-1 and PEA3. J Biol Chem 2002, 277:18649-18657.

36. Benbow U, Brinckerhoff CE: The AP-1 site and MMP gene regulation: what is all the fuss about? Matrix Biol 1997, 15:519-526.

37. Hida K, Shindoh M, Yasuda M, Hanzawa M, Funaoka K, Kohgo T, Amemiya A, Totsuka Y, Yoshida K, Fujinaga K: Antisense E1AF transfection restrains oral cancer invasion by reducing matrix metalloproteinase activities. Am J Pathol 1997, 150:2125-2132.

38. Tower GB, Coon Cl, Belguise K, Chalbos D, Brinckerhoff CE: Fra-1 targets the AP-1 site/2G single nucleotide polymorphism (ETS site) in the MMP1 promoter. Eur J Biochem 2003, 270:4216-4225.

39. Kapila $S$, Xie $Y$, Wang W: Induction of MMP-1 (collagenase-1) by relaxin in fibrocartilaginous cells requires both the AP- 1 and PEA-3 promoter sites. Orthod Craniofac Res 2009, 12:178-186.

40. Shepherd TG, Kockeritz L, Szrajber MR, Muller WJ, Hassell JA: The pea3 subfamily ets genes are required for HER2/Neu-mediated mammary oncogenesis. Curr Biol 2001, 11:1739-1748.

41. Graves BJ, Petersen JM: Specificity within the ets family of transcription factors. Adv Cancer Res 1998, 75:1-55.

42. Sharrocks AD: The ETS-domain transcription factor family. Nat Rev Mol Cell Biol 2001, 2:827-837.

43. Oikawa T, Yamada T: Molecular biology of the Ets family of transcription factors. Gene 2003, 303:11-34. 
44. Bojović $B B$, Hassell JA: The transactivation function of the Pea3 subfamily Ets transcription factors is regulated by sumoylation. DNA Cell Biol 2008, 27:289-305.

45. Takahashi A, Higashino F, Aoyagi M, Yoshida K, Itoh M, Kobayashi M, Totsuka Y, Kohgo T, Shindoh M: E1AF degradation by a ubiquitinproteasome pathway. Biochem Biophys Res Commun 2005, 327:575-580

46. Wasylyk B, Hagman J, Gutierrez-Hartmann A: Ets transcription factors: nuclear effectors of the Ras-MAP-kinase signaling pathway. Trends Biochem Sci 1998, 23:213-216.

47. Evans CP, Stapp EC, Dall'Era MA, Juarez J, Yang JC: Regulation of u-PA gene expression in human prostate cancer. Int I Cancer 2001, 94:390-395.

48. Matsui K, Sugimori K, Motomura H, Ejiri N, Tsukada K, Kitajima I: PEA3 cooperates with c-Jun in regulation of HER2/neu transcription. Oncol Rep 2006, 16:153-158.

49. Curran T, Franza BR Jr: Fos and Jun: the AP-1 connection. Cell 1988, 55:395-397.

50. Hesselbrock DR, Kurpios N, Hassell JA, Watson MA, Fleming TP: PEA3, AP-1, and a unique repetitive sequence all are involved in transcriptional regulation of the breast cancer-associated gene, mammaglobin. Breast Cancer Res Treat 2005, 89:289-296.

51. Matthews CP, Colburn NH, Young MR: AP-1 a target for cancer prevention. Curr Cancer Drug Targets 2007, 7:317-324.

52. Angel P, Karin M: The role of Jun, Fos and the AP-1 complex in cellproliferation and transformation. Biochim Biophys Acta 1991, 1072:129-157.

53. Bièche I, Tozlu S, Girault I, Onody P, Driouch K, Vidaud M, Lidereau R. Expression of PEA3/ETAF/ETV4, an Ets-related transcription factor, in breast tumors: positive links to MMP2, NRG1 and CGB expression. Carcinogenesis 2004, 25:405-411.

54. Davidson B, Goldberg I, Tell L, Vigdorchik S, Baekelandt M, Berner A Kristensen GB, Reich R, Kopolovic J: The clinical role of the PEA3 transcription factor in ovarian and breast carcinoma in effusions. Clin Exp Metastasis 2004, 21:191-199.

55. Discenza MT, Vaz D, Hassell JA, Pelletier J: Activation of the WT1 tumor suppressor gene promoter by Pea3. FEBS Lett 2004, 560:183-191.

56. Firlej V, Ladam F, Brysbaert G, Dumont P, Fuks F, de Launoit Y, Benecke A, Chotteau-Lelievre A: Reduced tumorigenesis in mouse mammary cancer cells following inhibition of Pea3- or Erm-dependent transcription. J Cell Sci 2008, 121:3393-3402

57. Kinoshita J, Kitamura K, Tanaka S, Sugimachi K, Ishida M, Saeki H: Clinical significance of PEA3 in human breast cancer. Surgery 2002, 131 Suppl: S222-S225.

58. Xia WY, Lien HC, Wang SC, Pan Y, Sahin A, Kuo YH, Chang KJ, Zhou X, Wang $H$, Yu Z, Hortobagyi G, Shi DR, Hung MC: Expression of PEA3 and lack of correlation between PEA3 and HER-2/neu expression in breast cancer. Breast Cancer Res Treat 2006, 98.295-301.

59. Notch-1 (Homo Sapiens). [http://www.ncbi.nlm.nih.gov/gene/4851].

60. Notch-4 (Homo Sapien). [http://www.ncbi.nlm.nih.gov/gene/4855].

61. Baert JL, Monté D, Musgrove EA, Albagli O, Sutherland RL, de Launoit Y: Expression of the PEA3 group of ETS-related transcription factors in human breast-cancer cells. Int J Cancer 1997, 70:590-597.

62. Liu Y, Ludes-Meyers J, Zhang Y, Munoz-Medellin D, Kim HT, Lu C, Ge G, Schiff R, Hilsenbeck SG, Osborne CK, Ge G, Schiff R, Hilsenbeck SG, Osborne CK, Brown PH: Inhibition of AP-1 transcription factor causes blockade of multiple signal transduction pathways and inhibits breast cancer growth. Oncogene 2002, 21:7680-7689.

63. Miele L, Golde T, Osborne B: Notch signaling in cancer. Curr Mol Med 2006, 6:905-918.

64. Hida K, Shindoh M, Yoshida K, Kudoh A, Furaoka K, Kohgo T, Fujinaga K, Totsuka Y: Expression of E1AF, an ets-family transcription factor, is correlated with the invasive phenotype of oral squamous cell carcinoma. Oral Oncol 1997, 33:426-430.

65. Kaya M, Yoshida K, Higashino F, Mitaka T, Ishii S, Fujinaga K: A single etsrelated transcription factor, E1AF, confers invasive phenotype on human cancer cells. Oncogene 1996, 12:221-227.

66. Benz CC, O'Hagan RC, Richter B, Scott GK, Chang CH, Xiong X, Chew K, Ljung BM, Edgerton $S$, Thor A, Hassell JA: HER2/Neu and the Ets transcription activator PEA3 are coordinately upregulated in human breast cancer. Oncogene 1997, 15:1513-1525.

67. Chotteau-Lelievre A, Montesano R, Soriano J, Soulie P, Desbiens $X$ de Launoit $Y$ : PEA3 transcription factors are expressed in tissues undergoing branching morphogenesis and promote formation of duct- like structures by mammary epithelial cells in vitro. Dev Biol 2003 259:241-257.

68. Shepherd T, Hassell JA: Role of Ets transcription factors in mammary gland development and oncogenesis. J Mammary Gland Biol Neoplasia 2001, 6:129-140

69. Nakamura T, Tsuchiya K, Watanabe M: Crosstalk between Wnt and Notch signaling in intestinal epithelial cell fate decision. J Gastroenterol 2007, 42:705-710,

70. Okamoto R, Tsuchiya K, Watanabe M: [Regulation of epithelial cell differentiation and regeneration in IBD] [in Japanese]. Nippon Shokakibyo Gakkai Zasshi 2007, 104:1165-1171.

71. Kopan R, llagan MX: The canonical Notch signaling pathway: unfolding the activation mechanism. Cell 2009, 137:216-233.

72. Myers E, Hill AD, Kelly G, McDermott EW, O'Higgins NJ, Young LS: A positive role for PEA3 in HER2-mediated breast tumour progression. $\mathrm{Br} J$ Cancer 2006, 95:1404-1409.

73. Davidson B, Konstantinovsky S, Nielsen S, Dong HP, Berner A, Vyberg M, Reich R: Altered expression of metastasis-associated and regulatory molecules in effusions from breast cancer patients: a novel model for tumor progression. Clin Cancer Res 2004, 10:7335-7346.

74. Song KS, Kim K, Chung KC, Seol JH, Yoon JH: Interaction of SOCS3 with NonO attenuates IL-1 $\beta$-dependent MUC8 gene expression. Biochem Biophys Res Commun 2008, 377:946-951.

75. Moellering RE, Cornejo M, Davis TN, Del Bianco C, Aster JC, Blacklow SC, Kung AL, Gilliland DG, Verdine GL, Bradner JE: Direct inhibition of the NOTCH transcription factor complex. Nature 2009, 462:182-188.

doi: $10.1186 / \mathrm{bcr} 2900$

Cite this article as: Clementz et al: NOTCH-1 and NOTCH-4 are novel gene targets of PEA3 in breast cancer: novel therapeutic implications. Breast Cancer Research 2011 13:R63.

\section{Submit your next manuscript to BioMed Central and take full advantage of:}

- Convenient online submission

- Thorough peer review

- No space constraints or color figure charges

- Immediate publication on acceptance

- Inclusion in PubMed, CAS, Scopus and Google Scholar

- Research which is freely available for redistribution

Submit your manuscript at www biomedcentral com/submit
C Biomed Central 